\title{
Radiative effects of interannually varying vs. interannually invariant aerosol emissions from fires
}

\author{
Benjamin S. Grandey ${ }^{1}$, Hsiang-He Lee ${ }^{1}$, and Chien Wang ${ }^{2,1}$ \\ ${ }^{1}$ Center for Environmental Sensing and Modeling, Singapore-MIT Alliance for Research and Technology, Singapore \\ ${ }^{2}$ Center for Global Change Science, Massachusetts Institute of Technology, Cambridge, Massachusetts, USA \\ Correspondence to: Benjamin S. Grandey (benjamin@ smart.mit.edu)
}

Received: 8 July 2016 - Published in Atmos. Chem. Phys. Discuss.: 26 July 2016

Revised: 12 October 2016 - Accepted: 31 October 2016 - Published: 23 November 2016

\begin{abstract}
Open-burning fires play an important role in the earth's climate system. In addition to contributing a substantial fraction of global emissions of carbon dioxide, they are a major source of atmospheric aerosols containing organic carbon, black carbon, and sulfate. These "fire aerosols" can influence the climate via direct and indirect radiative effects. In this study, we investigate these radiative effects and the hydrological fast response using the Community Atmosphere Model version 5 (CAM5). Emissions of fire aerosols exert a global mean net radiative effect of $-1.0 \mathrm{~W} \mathrm{~m}^{-2}$, dominated by the cloud shortwave response to organic carbon aerosol. The net radiative effect is particularly strong over boreal regions. Conventionally, many climate modelling studies have used an interannually invariant monthly climatology of emissions of fire aerosols. However, by comparing simulations using interannually varying emissions vs. interannually invariant emissions, we find that ignoring the interannual variability of the emissions can lead to systematic overestimation of the strength of the net radiative effect of the fire aerosols. Globally, the overestimation is $+23 \%\left(-0.2 \mathrm{~W} \mathrm{~m}^{-2}\right)$. Regionally, the overestimation can be substantially larger. For example, over Australia and New Zealand the overestimation is $+58 \%\left(-1.2 \mathrm{~W} \mathrm{~m}^{-2}\right)$, while over Boreal Asia the overestimation is $+43 \%\left(-1.9 \mathrm{~W} \mathrm{~m}^{-2}\right)$. The systematic overestimation of the net radiative effect of the fire aerosols is likely due to the non-linear influence of aerosols on clouds. However, ignoring interannual variability in the emissions does not appear to significantly impact the hydrological fast response. In order to improve understanding of the climate system, we need to take into account the interannual variability of aerosol emissions.
\end{abstract}

\section{Introduction}

There are many types of open-burning fires, caused by both natural and human influences. Broad categories include agricultural waste burning, grassland fire, peat fire, and various types of forest fire (van der Werf et al., 2010). In addition to producing heat, these fires emit pollutants into the atmosphere. One such pollutant is carbon dioxide, contributing to climate change - Page et al. (2002) estimate that the largescale burning of peat and forests in 1997 in Indonesia alone emitted the equivalent of 13-40\% of global annual emissions of carbon dioxide from fossil fuels. Other pollutants include aerosols, containing organic carbon, black carbon, and sulfate. These aerosols have a negative impact on air quality and human health (Lelieveld et al., 2015).

Aerosols also affect climate both regionally and globally. Aerosols can scatter and absorb incoming sunlight, cooling the earth's surface, an effect known as the "direct aerosol effect" (Haywood and Boucher, 2000). Absorbing aerosols, such as black carbon, warm the atmosphere, potentially affecting cloud formation (the "semi-direct effect"; Ackerman et al., 2000). Hygroscopic aerosols, such as sulfate, also play an important role in cloud formation, acting as the cloud condensation nuclei onto which cloud droplets condense. Hence, changing the availability of hygroscopic aerosols may affect the droplet size and number in clouds, potentially changing cloud reflectivity (the "cloud albedo effect" or "first indirect effect"; Twomey, 1974, 1977) and cloud lifetime (the "cloud lifetime effect" or "second indirect effect"; Albrecht, 1989). In addition to these two indirect effects, other aerosol effects on clouds have also been proposed, including a glaciation indirect effect (Lohmann, 2002) and the convective invigoration hypothesis (Andreae et al., 2004; Rosenfeld et al., 2008). 
For further discussion on possible aerosol effects on clouds, readers are referred to the review papers written by Lohmann and Feichter (2005), Tao et al. (2012), and Rosenfeld et al. (2014).

Surface cooling and atmospheric heating perturb regional temperature gradients, potentially affecting large-scale circulations such as monsoon systems. For example, many studies have suggested that aerosols impact the South Asian monsoon (e.g. Chung et al., 2002; Lau et al., 2006; Wang et al., 2009; Bollasina et al., 2011; Lee et al., 2013; Lee and Wang, 2015). Remote impacts are also possible. For example, we have recently demonstrated that anthropogenic emissions of aerosols from Asia may affect rainfall in remote locations such as Australia and the Sahel (Grandey et al., 2016). Remote impacts have also been explored by Menon (2002), Wang (2007, 2009), and Teng et al. (2012).

Most studies investigating the climate impacts of aerosols have focused on anthropogenic aerosols emitted by industry or power plants. Fewer studies have focused on the radiative and climate impacts of aerosols emitted from open-burning fires, which we will refer to as "fire aerosols", the focus of our current study.

Clark et al. (2015) recently investigated the radiative and climate effects of sub-monthly variability in fire emissions. They found that the "monthly-mean emissions approximation holds roughly in the tropics, where fires are more frequent and less episodic; however it does not perform as well in the boreal regions" (Clark et al., 2015). Jeong and Wang (2010) demonstrated the importance of seasonal variation in the emissions of fire aerosols. They found that the "seasonality of biomass burning emissions uniquely affects the global distributions of convective clouds and precipitation" (Jeong and Wang, 2010). In light of the findings of Jeong and Wang (2010), we use seasonally varying emissions in our study. Beyond seasonal variability, Feng and Christopher (2014) and Sena and Artaxo (2015) showed that the direct radiative effects of fire aerosols also exhibit interannual variability, something that is not taken into account in most climate modelling studies. We complement the sub-monthly focus of Clark et al. (2015) and the seasonal focus of Jeong and Wang (2010) by investigating interannually varying emissions.

Three of the above-mentioned studies (Jeong and Wang, 2010; Feng and Christopher, 2014; Sena and Artaxo, 2015) considered the direct radiative effects of fire aerosols but did not consider other radiative effects. However, as pointed out by Jacobson (2014), the radiative effects of fire aerosols are not limited to the direct effect. Jiang et al. (2016) found that the indirect effects of fire aerosols may be substantially larger than the direct effect. Chuang et al. (2002), Jones et al. (2007), Unger et al. (2010), Ward et al. (2012), Clark et al. (2015), and Veira et al. (2015) all appreciated the importance of modelling the indirect effects of fire aerosols. In addition to representing the direct and semi-direct effects, the aerosolclimate model used in this study also includes a representation of indirect effects on stratiform clouds. However, some other possible effects, such as cloud absorption effects (Jacobson, 2014), are not represented.

Using the ECHAM6-HAM2 aerosol-climate model, Veira et al. (2015) recently investigated the influence of fire emission height. Although they found that emission height can influence the radiative effects of fire aerosols, they concluded that, "Significant improvements in aerosol wildfire modelling likely depend on better emission inventories and aerosol process modelling rather than on improved emission height parametrizations" (Veira et al., 2015). In this study, we prescribe emission heights according to fire type, as described in the Method section.

Building on these previous studies, we explore the radiative effects associated with interannually varying emissions of fire aerosols. We use Global Fire Emissions Database (GFED) aerosol emissions to drive a global aerosol-climate model. We quantify the radiative effects for the globe and several different regions (Fig. 1). We also discuss the hydrological fast response. In the Discussion section, we focus on one primary research question: how do the effects of interannually varying emissions differ from those of interannually invariant climatological emissions? In the context of this research question, we consider the non-linear influence of aerosols on clouds.

\section{Method}

\subsection{Model configuration}

The Community Earth System Model (CESM) version 1.2.2, which includes the Community Atmosphere Model version 5 (CAM5) (Neale et al., 2012), is used. CAM5 contains a modal aerosol model with three log-normal modes (MAM3) (Liu et al., 2012). Aerosol direct and semi-direct effects are included via coupling between the aerosols and the radiation. Aerosol indirect effects on stratiform clouds are included via coupling between the aerosols and the stratiform cloud microphysics (Morrison and Gettelman, 2008; Gettelman et al., 2010). As a result of these indirect effects (Ghan et al., 2012), CESM1-CAM5 produces a relatively strong total aerosol radiative effect compared to many other global climate models (Table 7 of Shindell et al., 2013). CAM5 does not include a representation of aerosol indirect effects on convective cloud microphysics. However, the aerosols may indirectly impact convection via interaction with the radiation.

A finite volume grid with a horizontal resolution of approximately $1.9^{\circ} \times 2.5^{\circ}$ and 30 levels is used for CAM5. The land model is run at the same horizontal resolution. Greenhouse gas concentrations, sea-surface temperatures (SSTs), and sea-ice are prescribed using year-2000 climatological values.

The prescribed-SST approach is suitable for diagnosing radiative flux perturbations (RFPs) (Haywood et al., 2009) and the hydrological fast response (Bala et al., 2010) associ- 


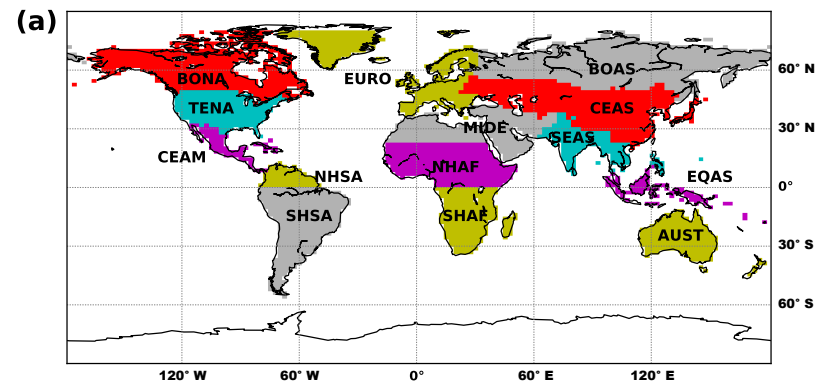

(b)

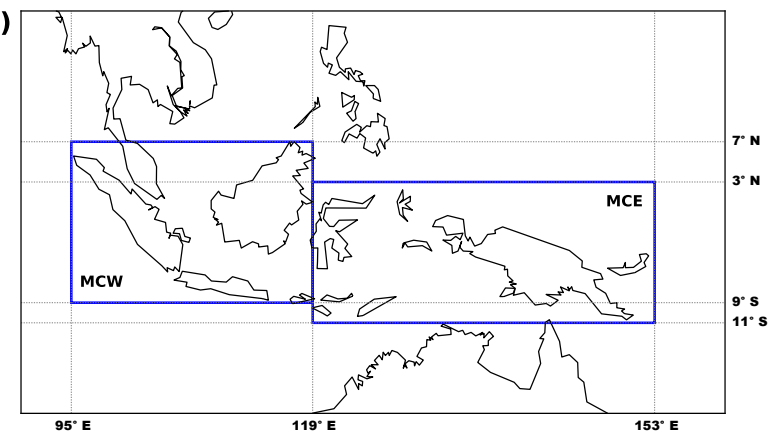

Figure 1. (a) The GFED4.0s basis regions, regridded to the model resolution of approximately $1.9^{\circ} \times 2.5^{\circ}$ using nearestneighbour interpolation: Boreal North America (BONA), Temperate North America (TENA), Central America (CEAM), Northern Hemisphere South America (NHSA), Southern Hemisphere South America (SHSA), Southern Hemisphere Africa (SHAF), Northern Hemisphere Africa (NHAF), the Middle East (MIDE), Europe (EURO), Boreal Asia (BOAS), Central Asia (CEAS), Southeast Asia (SEAS), Australia and New Zealand (AUST), and Equatorial Asia (EQAS). (b) The two regions used instead of EQAS in this study: the Western Maritime Continent (MCW), and the Eastern Maritime Continent (MCE). Unlike the land-only GFED4.0s basis regions, the two maritime continent regions both include ocean as well as land, due to the difficulty of distinguishing land from ocean at a resolution of $1.9^{\circ} \times 2.5^{\circ}$ over the maritime continent. In the other figures and tables, Northern Hemisphere is often abbreviated to $\mathrm{NH}$, while Southern Hemisphere is abbreviated to SH.

ated with aerosols. RFPs are diagnosed by calculating the difference in the top-of-atmosphere radiative flux between two prescribed-SST simulations forced with different aerosol emissions. In contrast to a strict definition of radiative forcing, the RFP approach allows clouds and precipitation to adjust to the aerosol forcing via fast feedback processes. Hence, RFPs allow quantification of the indirect effects of aerosols on clouds. To facilitate decomposition of the RFPs (Ghan, 2013), the radiation scheme is called twice at each radiation time step. The first radiation call includes all aerosol species. The second radiation call, which is purely diagnostic, excludes all aerosol species, allowing diagnosis of clean-sky fluxes.

\subsection{Emissions}

Emissions of organic carbon, black carbon, sulfur dioxide, primary sulfate, dimethyl sulfide, and secondary organic aerosol precursors mostly follow the default MAM3 emissions for year-2000. The exception is that fire emissions of organic carbon, black carbon, sulfur dioxide, and primary sulfate are modified.

As in the "interpolation method" simulation of Clark et al. (2015), monthly fire emissions are used in this study. Several fire emission inventories are available (van der Werf et al., 2010; Wiedinmyer et al., 2011; Kaiser et al., 2012). There is uncertainty associated with these fire emission inventories - for example, Lee et al. (2016) found that differences between two of these inventories contributes to uncertainty in modelled aerosol concentration over Southeast Asia. We have chosen to use monthly fire emissions from the Global Fire Emission Database version 4.0 with small fires included (GFED4.0s) (revised version of van der Werf et al., 2010), which has data available from 1997 onwards. The recommended GFED4.0s emission factors are used to convert partitioned dry matter emissions to emissions of organic carbon, black carbon, and sulfur dioxide. These emissions are then conservatively remapped from the GFED4.0s grid $\left(0.25^{\circ} \times 0.25^{\circ}\right)$ to the grid used in the MAM3 emissions files (approximately $1.9^{\circ} \times 2.5^{\circ}$ ).

Following Liu et al. (2012), emission height profiles are based on Table 4 of Dentener et al. (2006). For boreal forest fires, the boreal (Eurasia) emission height profile is used instead of the boreal (Canada) profile. The Dentener et al. (2006) height profiles are linearly interpolated to the higher resolution vertical levels used in the MAM3 emission files.

The GFED4.0s fire categories are subsequently mapped to the MAM3 emission sector categories. The GFED4.0s "agricultural waste burning" category corresponds to the MAM3 agricultural waste burning category, the GFED4.0s "savanna, grassland, and shrubland fires" category corresponds to the MAM3 grass fire category, and the GFED4.0s "boreal forest fires", "temperate forest fires", "tropical forest fires (deforestation and degradation)", and "peat fires" categories are combined into the MAM3 forest fire category. The resulting global and regional organic carbon, black carbon, and sulfur dioxide annual emissions for the different simulations (described below) are shown in Figs. 2 and S1-S5 in the Supplement. Globally, averaged across 1997 2006, fire emissions are responsible for $60 \%\left(18 \mathrm{Tg} \mathrm{yr}^{-1}\right)$ of the total organic carbon emissions of $30 \mathrm{Tg} \mathrm{yr}^{-1}, 28 \%$ $\left(2 \mathrm{Tg} \mathrm{yr}^{-1}\right)$ of the total black carbon emissions of $7 \mathrm{Tg} \mathrm{yr}^{-1}$, and $2 \%\left(2.6 \mathrm{Tg} \mathrm{yr}^{-1}\right)$ of the total sulfur dioxide emissions of $131 \mathrm{Tg} \mathrm{yr}^{-1}$. It is worth noting that the total black carbon emissions of $7 \mathrm{Tg} \mathrm{yr}^{-1}$ used in this study may represent an underestimate - Cohen and Wang (2014) estimate that global $\mathrm{BC}$ emissions are $17.8 \pm 5.6 \mathrm{Tg} \mathrm{yr}^{-1}$.

It is assumed that $2.5 \%$ of the sulfur dioxide is emitted as primary sulfate (Dentener et al., 2006; Liu et al., 2012). 

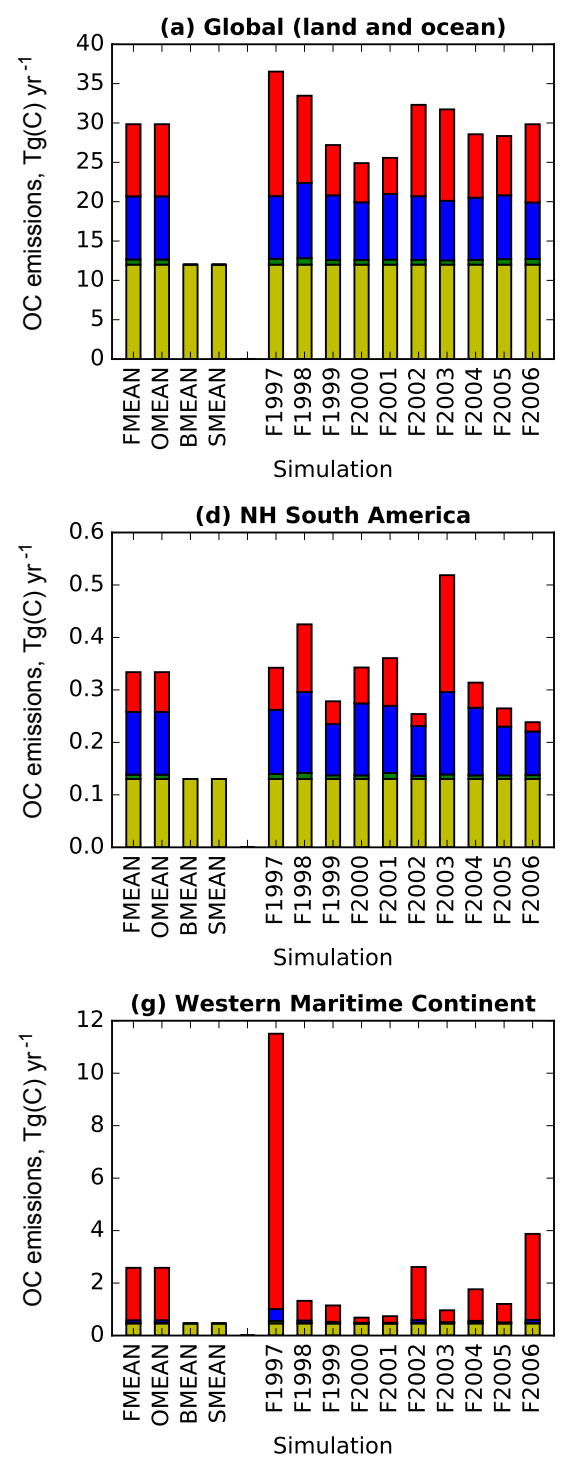

(b) Boreal North America

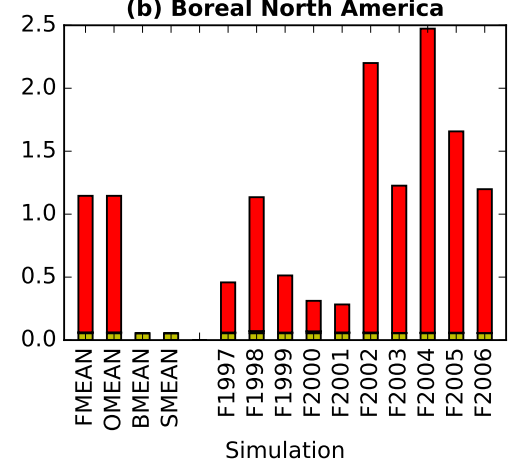

(e) Australia and New Zealand

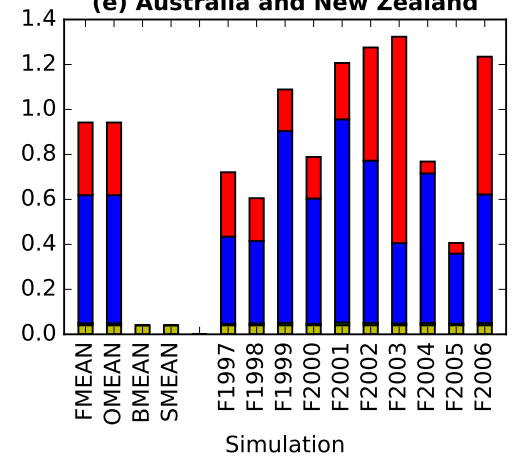

(h) SH South America

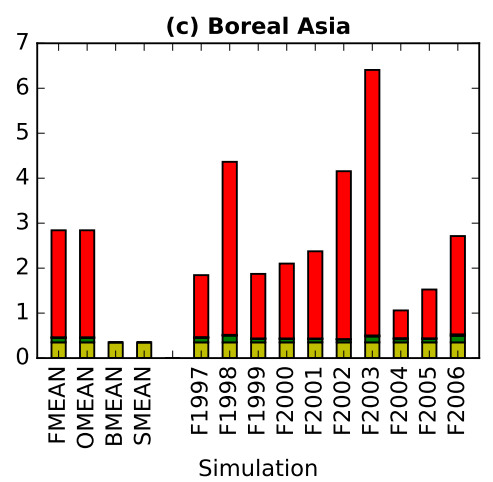

(f) SH Africa

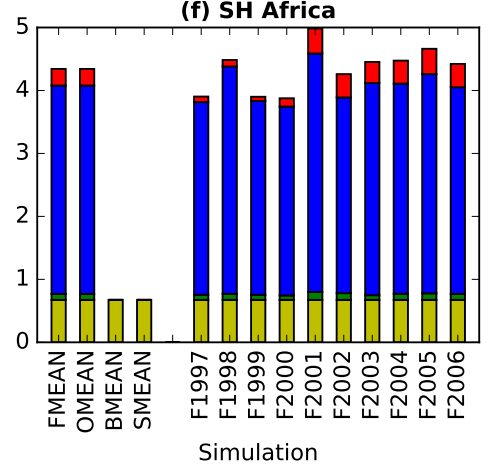

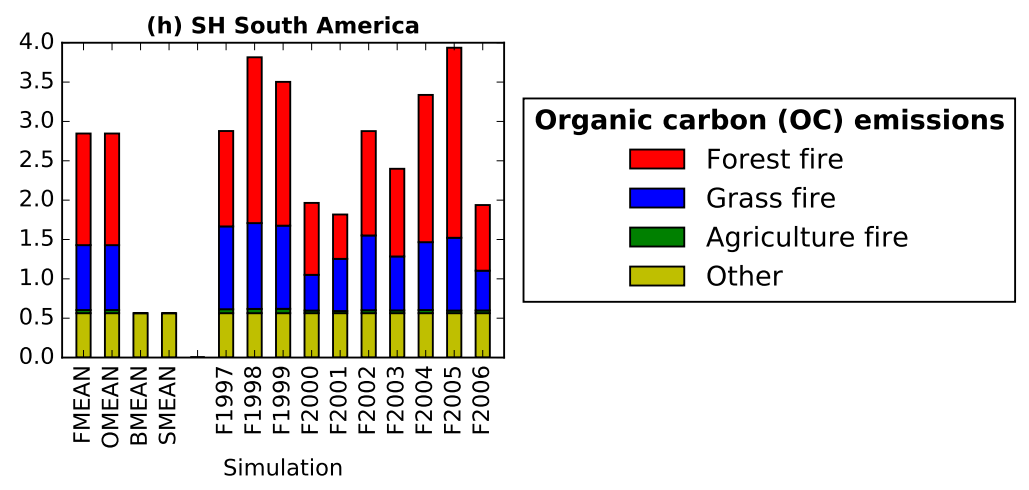

Figure 2. Organic carbon (OC) aerosol annual emissions for (a) the globe and (b-h) seven regions (see Fig. 1). The seven regions included here are those with the largest FMEAN-F0 net radiative flux perturbation differences (Table 1). "Other" refers to year-2000 emissions from non-fire sectors, such as domestic emissions and fossil fuel emissions from industry. Organic carbon emissions for another eight regions are shown in Fig. S1. Black carbon and sulfur dioxide emissions are shown in Figs. S2-S5.

Size distributions of emitted organic carbon, black carbon, and primary sulfate follow the size distributions described in the Supplement of Liu et al. (2012).

\subsection{Simulations}

Fifteen simulations are performed. The first of these, F0, is a control simulation. In F0, fire emissions of organic carbon, black carbon, sulfur dioxide, and primary sulfate are set to zero. In this paper, RFPs are calculated with respect to simulation F0, rather than a pre-industrial control.
Ten simulations use fire emissions for the 10 different years between 1997 and 2006. For example, F1997 uses year1997 fire emissions, F1998 uses year-1998 fire emissions etc. Together, this ensemble of 10 simulations is referred to as \{Fyyyy . Comparison of $\{$ Fyyyy $\}$ with F0 reveals the radiative effect of interannually varying emissions of fire aerosols. We refer to this as the "revised" approach, in contrast to the "conventional" approach described in the next paragraph.

In contrast to the $\{$ Fyyyy ensemble, the FMEAN simulation uses mean emissions averaged across 1997-2006 for each month. The seasonal cycle is retained, but interannual variability is removed. In other words, the FMEAN emis- 
Table 1. Net (shortwave plus longwave) top-of-atmosphere radiative flux perturbation (RFP) differences for different simulation combinations and regions (see Fig. 1). Area-weighting has been applied. Combined standard errors have been calculated using corrected sample standard deviations, using annual regional mean data as the input - e.g. the standard error for the global \{Fyyyy\}-F0 difference was calculated using $\sqrt{\frac{s_{\{\mathrm{Fyyyy}\}}^{2}}{N_{\{\mathrm{Fyyyy}\}}}+\frac{s_{\mathrm{F} 0}^{2}}{N_{\mathrm{F} 0}}}$, where $s_{\{\text {Fyyyy }\}}$ and $s_{\mathrm{F} 0}$ are the corrected sample standard deviations, and $N_{\{\mathrm{Fyyyy}\}}=120$ and $N_{\mathrm{F} 0}=42$ are the sample sizes. Significance has been tested using Welch's $t$ test, using annual regional mean data as the input: ${ }^{\text {a }}$ indicates differences that are statistically significant at two-tailed $p<0.05$, and ${ }^{\mathrm{b}}$ indicates differences that are statistically significant at two-tailed $p<0.01$. The regions have been ranked according the FMEAN-F0 net RFP strength. A horizontal line is used to indicate the seven regions that receive more focus in the Results section.

\begin{tabular}{lrrr}
\hline & \multicolumn{3}{r}{ Net radiative flux perturbation (RFP), W m } \\
\cline { 2 - 4 } Region & $\begin{array}{r}\text { FMEAN-F0 } \\
\text { conventional }\end{array}$ & $\begin{array}{r}\text { \{Fyyy }\} \text { F0 } \\
\text { revised }\end{array}$ & $\begin{array}{r}\text { FMEAN-\{Fyyy }\} \\
\text { difference }\end{array}$ \\
\hline Global (land and ocean) & $-1.26 \pm 0.03^{\mathrm{b}}$ & $-1.02 \pm 0.03^{\mathrm{b}}$ & $-0.24 \pm 0.03^{\mathrm{b}}$ \\
\hline Boreal North America & $-6.52 \pm 0.18^{\mathrm{b}}$ & $-4.92 \pm 0.21^{\mathrm{b}}$ & $-1.60 \pm 0.21^{\mathrm{b}}$ \\
Boreal Asia & $-6.23 \pm 0.28^{\mathrm{b}}$ & $-4.35 \pm 0.17^{\mathrm{b}}$ & $-1.88 \pm 0.27^{\mathrm{b}}$ \\
NH South America & $-3.83 \pm 0.21^{\mathrm{b}}$ & $-3.67 \pm 0.18^{\mathrm{b}}$ & $-0.16 \pm 0.18$ \\
Australia and New Zealand & $-3.30 \pm 0.41^{\mathrm{b}}$ & $-2.10 \pm 0.31^{\mathrm{b}}$ & $-1.21 \pm 0.36^{\mathrm{b}}$ \\
SH Africa & $-3.30 \pm 0.31^{\mathrm{b}}$ & $-3.21 \pm 0.27^{\mathrm{b}}$ & $-0.10 \pm 0.26$ \\
Western Maritime Continent & $-2.46 \pm 0.24^{\mathrm{b}}$ & $-1.65 \pm 0.19^{\mathrm{b}}$ & $-0.81 \pm 0.22^{\mathrm{b}}$ \\
SH South America & $-1.78 \pm 0.17^{\mathrm{b}}$ & $-1.71 \pm 0.16^{\mathrm{b}}$ & $-0.07 \pm 0.13$ \\
\hline Central America & $-1.60 \pm 0.29^{\mathrm{b}}$ & $-1.14 \pm 0.26^{\mathrm{b}}$ & $-0.46 \pm 0.22^{\mathrm{a}}$ \\
Eastern Maritime Continent & $-1.45 \pm 0.20^{\mathrm{b}}$ & $-1.22 \pm 0.18^{\mathrm{b}}$ & $-0.24 \pm 0.17$ \\
Temperate North America & $-0.98 \pm 0.32^{\mathrm{b}}$ & $-1.25 \pm 0.26^{\mathrm{b}}$ & $+0.27 \pm 0.28$ \\
Central Asia & $-0.92 \pm 0.28^{\mathrm{b}}$ & $-0.73 \pm 0.22^{\mathrm{b}}$ & $-0.19 \pm 0.22$ \\
NH Africa & $-0.79 \pm 0.17^{\mathrm{b}}$ & $-0.73 \pm 0.13^{\mathrm{b}}$ & $-0.06 \pm 0.16$ \\
Southeast Asia & $-0.61 \pm 0.23^{\mathrm{b}}$ & $-0.23 \pm 0.20$ & $-0.39 \pm 0.19^{\mathrm{a}}$ \\
Europe & $-0.27 \pm 0.33$ & $-0.14 \pm 0.24$ & $-0.13 \pm 0.28$ \\
Middle East & $-0.14 \pm 0.12$ & $-0.08 \pm 0.10$ & $-0.07 \pm 0.10$ \\
\hline
\end{tabular}

sions consist of a monthly climatology. We refer to this as the conventional approach. Comparison of FMEAN (conventional) with $\{$ Fyyyy $\}$ (revised) reveals the influence of ignoring interannual variability.

OMEAN combines the organic carbon emissions of FMEAN with the black carbon, sulfur dioxide, and primary sulfate emissions of F0 (i.e. zero emissions of black carbon and sulfur from fires). Similarly, BMEAN combines the black carbon emissions of FMEAN with the organic carbon, sulfur dioxide, and primary sulfate emissions of F0, and SMEAN combines the sulfur dioxide and primary sulfate emissions of FMEAN with the black carbon and organic carbon emissions of F0. Comparison of OMEAN, BMEAN, and SMEAN with FMEAN reveals the relative contributions of organic carbon, black carbon, and sulfur dioxide.

The first 2 years of each simulation are treated as spin-up. Simulations F0 and FMEAN are each run for 44 years, providing an analysis period of 42 years. Simulations OMEAN, BMEAN, SMEAN, and each member of the \{Fyyyy $\}$ ensemble (i.e. F1997 etc.) are each run for 14 years, providing an analysis period of 12 years. The total analysis period for $\{$ Fyyyy $\}$ is 120 years, because $\{$ Fyyyy consists of 10 separate simulations. When deciding the simulation lengths, we sought a balance between the improved statistical power of larger sample sizes and the computational expense of the simulations.

\section{Results}

\subsection{Radiative effects of fire aerosols}

\subsubsection{Global mean}

In most global climate modelling studies, a monthly climatology of aerosol emissions from fires is used, hence the interannual variability of the emissions is ignored. Here, we also start with this conventional approach of ignoring interannual variability.

The conventional global mean net RFP associated with fire aerosols is $-1.3 \mathrm{~W} \mathrm{~m}^{-2}$ (Table 1). Note that this RFP is relative to simulation $\mathrm{F0}$ which has zero emissions of fire aerosols. If a different reference, for example year- 1850 emissions of fire aerosols, were to be chosen, the global mean net RFP would be smaller in magnitude. The global mean net RFP of $-1.3 \mathrm{~W} \mathrm{~m}^{-2}$ is comparable to that found by Clark et al. (2015, interpolation method simulation), who also used 

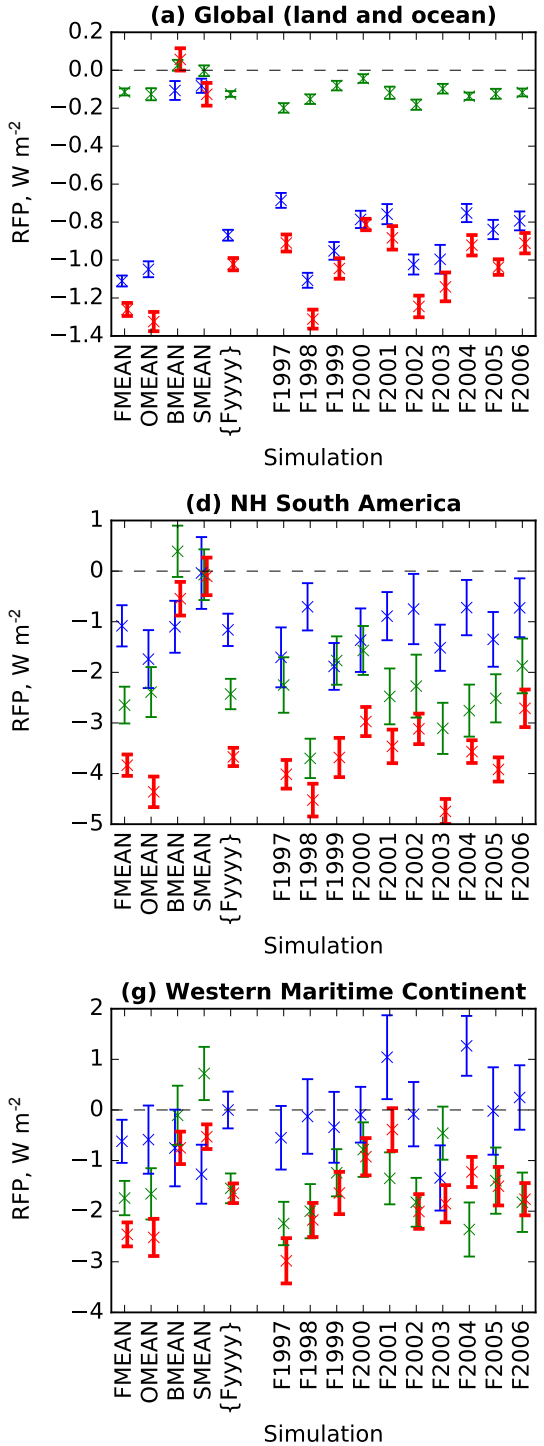
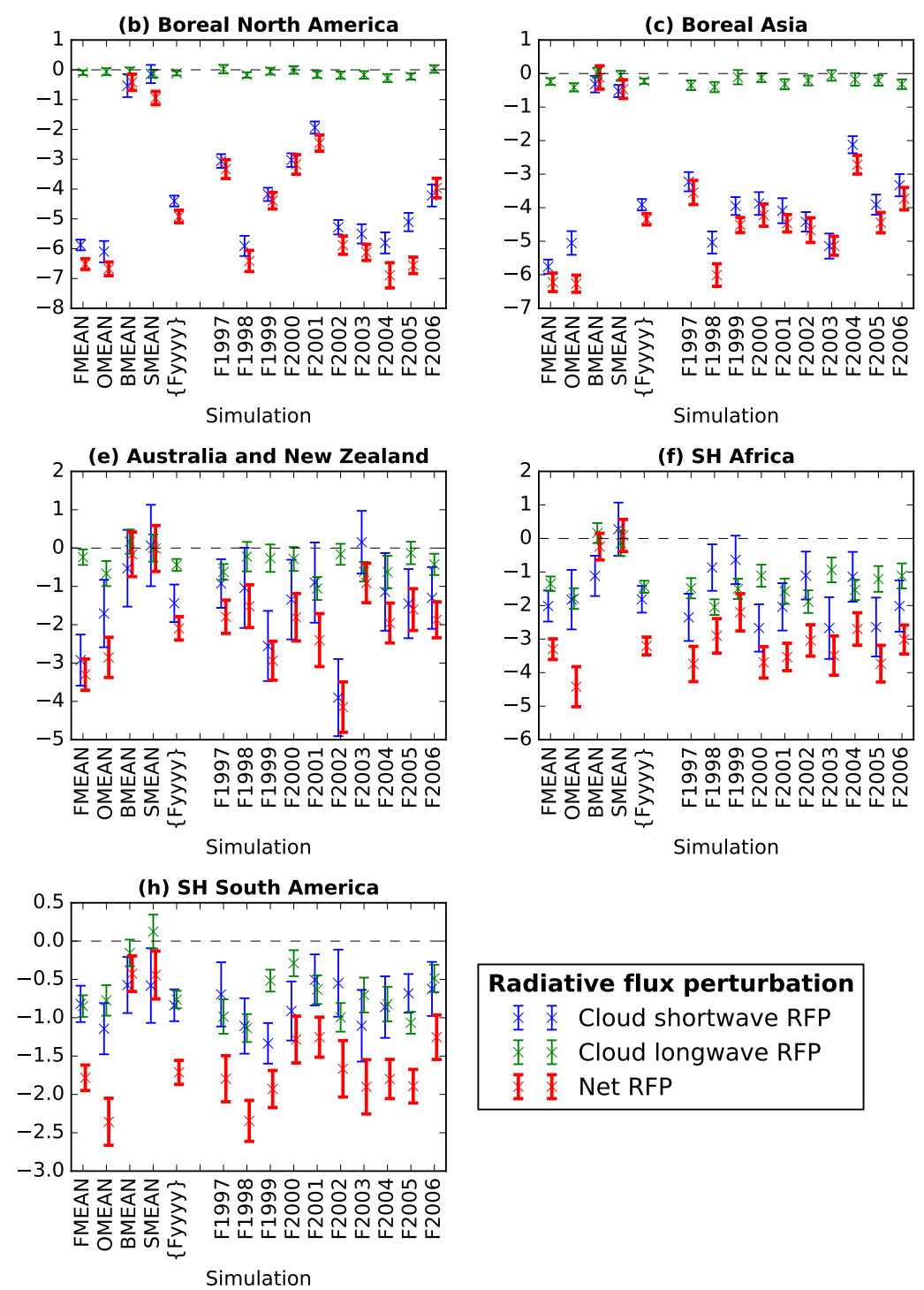

\section{Radiative flux perturbation}

巫 Cloud shortwave RFP

巫 Cloud longwave RFP

王 Net RFP

Figure 3. Cloud shortwave, cloud longwave, and net (all components, shortwave plus longwave) top-of-atmosphere radiative flux perturbations (RFPs) for the globe and seven regions. Results for another eight regions are shown in Fig. S6. The RFPs are relative to simulation F0 and are area-weighted. Error bars represent combined standard error, using annual regional mean data as the input - e.g. for the F1997 net RFP error bars, the combined standard error equals $\sqrt{\frac{s_{\mathrm{F} 0}^{2}}{N_{\mathrm{F} 0}}+\frac{s_{\mathrm{F} 1997}^{2}}{N_{\mathrm{F} 1997}}}$, where $s_{\mathrm{F} 0}$ and $s_{\mathrm{F} 1997}$ are the corrected sample standard deviations, and $N_{\mathrm{F} 0}=42$ and $N_{\mathrm{F} 1997}=12$ are the sample sizes.

CAM5. This value, which is dominated by the shortwave (see below), is also comparable to two previous estimates of the shortwave forcing associated with fire aerosols: an estimate of $-1.4 \mathrm{~W} \mathrm{~m}^{-2}$ by Ward et al. (2012, their Table 5), who also used CAM5, and an estimate of $-1.2 \mathrm{~W} \mathrm{~m}^{-2}$ by Chuang et al. (2002), who used CCM1/GRANTOUR to quantify the cloud albedo effect only. However, a value of $-1.3 \mathrm{~W} \mathrm{~m}^{-2}$ is much larger than ECHAM6-HAM2's fire aerosol net RFP of $-0.2 \mathrm{~W} \mathrm{~m}^{-2}$ (Veira et al., 2015). This discrepancy appears to be primarily due to differences in the parameteri- zation of indirect effects, especially the sensitivity of stratiform clouds to organic carbon aerosol emissions (see below). CESM-CAM5, which produces an anthropogenic aerosol year-2000-year-1850 net RFP of $-1.5 \mathrm{~W} \mathrm{~m}^{-2}$ (Ghan et al., 2012), is known to produce a stronger net RFP than many other global climate models (Shindell et al., 2013). In addition to large uncertainty associated with the parameterization of indirect effects, there is also uncertainty associated with the emissions of fire aerosols. 
Table 2. Cloud shortwave top-of-atmosphere radiative flux perturbation (RFP) differences for different simulation combinations and regions. Combined standard errors have been calculated. Significance has been tested using Welch's $t$ test: ${ }^{\text {a }}$ indicates differences that are statistically significant at two-tailed $p<0.05$, and ${ }^{\mathrm{b}}$ indicates differences that are statistically significant at two-tailed $p<0.01$.

\begin{tabular}{lcrr}
\hline & \multicolumn{2}{c}{ Cloud shortwave radiative flux perturbation (RFP), W m } \\
\cline { 2 - 4 } Region & $\begin{array}{r}\text { FMEAN-F0 } \\
\text { conventional }\end{array}$ & $\begin{array}{r}\{\text { Fyyy }\}-F 0 \\
\text { revised }\end{array}$ & $\begin{array}{r}\text { FMEAN-\{Fyyyy }\} \\
\text { difference }\end{array}$ \\
\hline Global (land and ocean) & $-1.11 \pm 0.03^{\mathrm{b}}$ & $-0.87 \pm 0.03^{\mathrm{b}}$ & $-0.24 \pm 0.03^{\mathrm{b}}$ \\
\hline Boreal North America & $-5.88 \pm 0.18^{\mathrm{b}}$ & $-4.40 \pm 0.18^{\mathrm{b}}$ & $-1.47 \pm 0.20^{\mathrm{b}}$ \\
Boreal Asia & $-5.76 \pm 0.21^{\mathrm{b}}$ & $-3.91 \pm 0.17^{\mathrm{b}}$ & $-1.85 \pm 0.21^{\mathrm{b}}$ \\
NH South America & $-1.08 \pm 0.41^{\mathrm{b}}$ & $-1.16 \pm 0.32^{\mathrm{b}}$ & $+0.08 \pm 0.33$ \\
Australia and New Zealand & $-2.92 \pm 0.67^{\mathrm{b}}$ & $-1.44 \pm 0.49^{\mathrm{b}}$ & $-1.48 \pm 0.59^{\mathrm{a}}$ \\
SH Africa & $-2.01 \pm 0.46^{\mathrm{b}}$ & $-1.81 \pm 0.40^{\mathrm{b}}$ & $-0.20 \pm 0.39$ \\
Western Maritime Continent & $-0.62 \pm 0.43$ & $-0.00 \pm 0.36$ & $-0.62 \pm 0.36$ \\
SH South America & $-0.82 \pm 0.24^{\mathrm{b}}$ & $-0.84 \pm 0.21^{\mathrm{b}}$ & $+0.02 \pm 0.18$ \\
\hline Central America & $-1.75 \pm 0.47^{\mathrm{b}}$ & $-1.08 \pm 0.41^{\mathrm{a}}$ & $-0.68 \pm 0.37$ \\
Eastern Maritime Continent & $-0.62 \pm 0.37$ & $-0.72 \pm 0.33^{\mathrm{a}}$ & $+0.09 \pm 0.30$ \\
Temperate North America & $-1.05 \pm 0.37^{\mathrm{b}}$ & $-1.30 \pm 0.31^{\mathrm{b}}$ & $+0.26 \pm 0.31$ \\
Central Asia & $-0.30 \pm 0.28$ & $-0.22 \pm 0.23$ & $-0.08 \pm 0.23$ \\
NH Africa & $-0.28 \pm 0.35$ & $-0.17 \pm 0.28$ & $-0.11 \pm 0.28$ \\
Southeast Asia & $-0.20 \pm 0.44$ & $+0.41 \pm 0.37$ & $-0.61 \pm 0.37$ \\
Europe & $+0.48 \pm 0.41$ & $+0.10 \pm 0.30$ & $+0.38 \pm 0.36$ \\
Middle East & $-0.37 \pm 0.30$ & $-0.12 \pm 0.21$ & $-0.25 \pm 0.25$ \\
\hline
\end{tabular}

This global mean net RFP of $-1.3 \mathrm{~W} \mathrm{~m}^{-2}$ is dominated by the cloud shortwave RFP of $-1.1 \mathrm{~W} \mathrm{~m}^{-2}$ (Fig. 3a, Table 2), primarily driven by the organic carbon emissions (Fig. 3a), in general agreement with the findings of Jiang et al. (2016). The organic carbon emissions also drive a corresponding increase in global mean grid-box average liquid water path (Fig. S14a).

The cloud longwave RFP of $-0.1 \mathrm{~W} \mathrm{~m}^{-2}$ (Fig. 3a, Table $\mathrm{S} 1$ in the Supplement) is also driven by the organic carbon emissions (Fig. 3a). Interestingly, again in agreement with Jiang et al. (2016), the cloud longwave RFP associated with the fire aerosols is negative, in contrast to the results of Ghan et al. (2012), who found a positive cloud longwave RFP associated with anthropogenic aerosols (see also Gettelman et al., 2012). The occurrence of negative cloud longwave RFP values corresponds to decreasing fractional cover of high clouds and decreasing ice water path, especially over equatorial land regions (Fig. S11).

The organic carbon emissions drive a small surface albedo RFP of $-0.1 \mathrm{~W} \mathrm{~m}^{-2}$ (Fig. 4a, Table S2), due to increasing snow cover in Boreal North America (see below) and other parts of the world, likely in response to the cloud shortwave RFP. The organic carbon emissions also drive a small direct effect RFP but this is more than offset by the positive direct effect RFP of the black carbon emissions (Fig. 4a), resulting in a small positive direct effect RFP overall (Table S3).

When the emissions for individual years are used to drive separate simulations in the 10-member $\{$ Fyyyy ensemble, the interannual variability of the RFP components is revealed. Most of the variability in global mean net RFP is dominated by the cloud shortwave RFP component (Fig. 3a). The global mean net RFP ranges from $-0.8 \mathrm{~W} \mathrm{~m}^{-2}$ in F2000, which has the lowest organic carbon emissions, to $-1.3 \mathrm{~W} \mathrm{~m}^{-2}$ in $\mathrm{F} 1998$, which has the second highest organic carbon emissions (Figs. 2a, 3a). Interestingly, this maximum net RFP of $-1.3 \mathrm{~W} \mathrm{~m}^{-2}$ in F1998 is comparable to the conventional global mean net RFP, suggesting that the global impact of the fire aerosols may saturate (see Discussion). The simulation with the highest organic carbon emissions (Fig. 2a), F1997, has a comparatively weak global mean net RFP of $-0.9 \mathrm{~W} \mathrm{~m}^{-2}$ (Fig. 3a), demonstrating that the global mean net RFP response is not a monotonic function of global annual organic carbon emissions (Fig. 5a). This suggests that the location and timing of emissions play an important role in determining the RFP response.

In contrast to the conventional approach of using interannually invariant emissions, comparison of $\{$ Fyyyy $\}$ with F0 reveals the mean effect of interannually varying emissions of fire aerosols. The revised global mean net RFP is $-1.0 \mathrm{~W} \mathrm{~m}^{-2}$ (Table 1). A conventional-revised difference of $-0.24 \mathrm{~W} \mathrm{~m}^{-2}$ is found (Table 1 ), primarily due to the cloud shortwave RFP component (Fig. 3a). Welch's $t$ test reveals that this difference is statistically significant (see Table 1 caption). These results indicate that the conventional approach of using interannually invariant fire aerosol emissions leads to a $23 \%$ overestimation of the negative RFP exerted by fire 

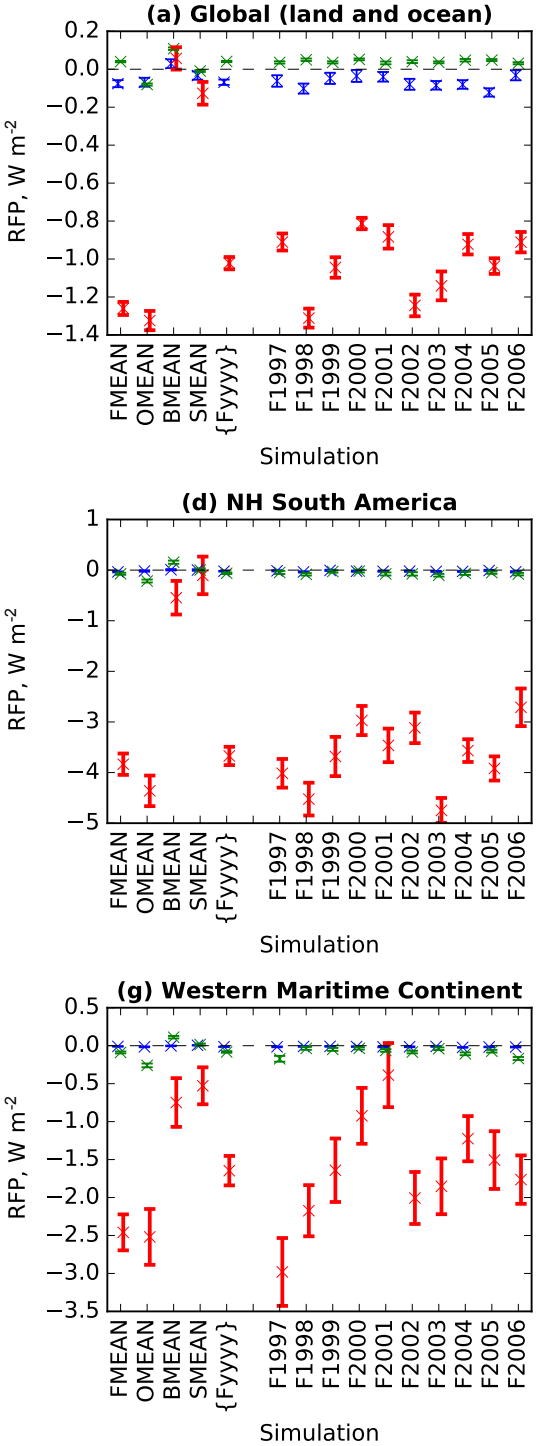

(b) Boreal North America

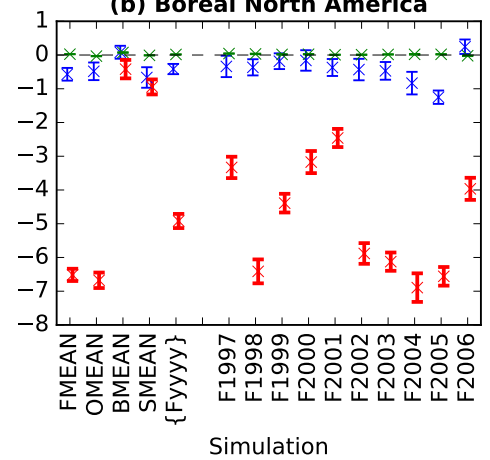

(e) Australia and New Zealand

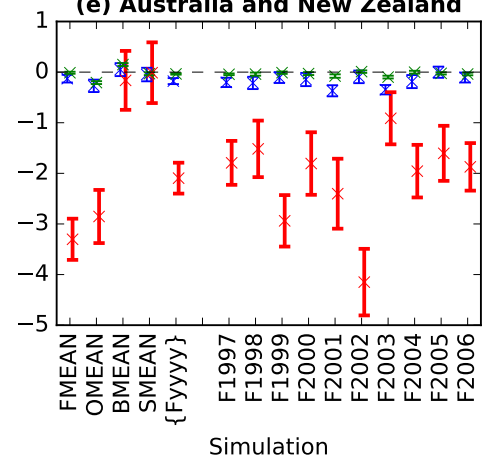

(h) SH South America

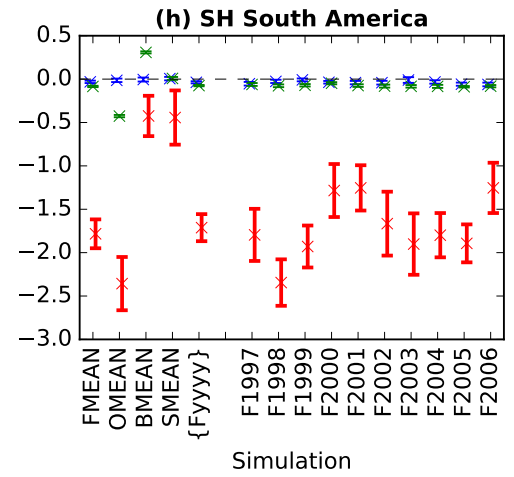

(c) Boreal Asia

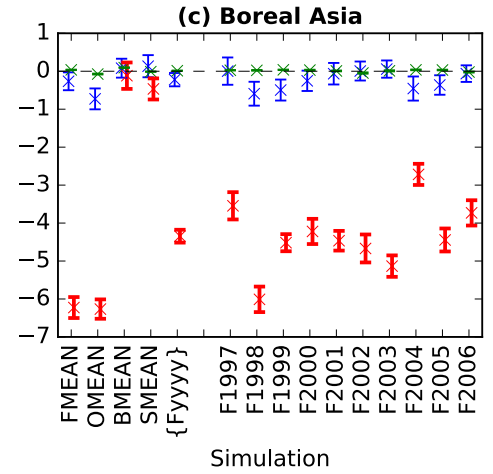

(f) SH Africa

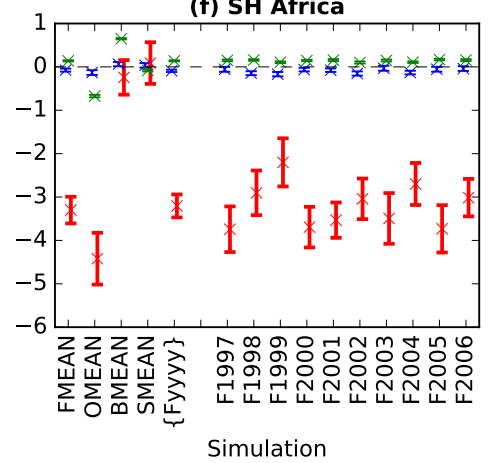

Radiative flux perturbation

来巫 Surface albedo RFP

巫巫 Direct effect RFP

I Net RFP

Figure 4. Surface albedo, aerosol direct effect, and net (all components, shortwave plus longwave) top-of-atmosphere radiative flux perturbations (RFPs) for the globe and seven regions. Results for another eight regions are shown in Fig. S7. The RFPs are relative to simulation F0. Error bars represent combined standard error (see Fig. 3 caption).

aerosols on the climate system (Fig. 5a). Further discussion on the effect of ignoring interannual variability can be found in the Discussion section.

\subsubsection{Global distribution}

The global distribution of the radiative effects associated with fire aerosols is highly inhomogeneous (Fig. 6a, b). Particularly strong net RFPs occur over high-latitude boreal regions, and parts of South America, Southern Hemisphere Africa, Australia, and the maritime continent. These regions will be discussed below.
Although the discussion below focuses on land regions, readers should note that the radiative effects of the fire aerosols are not limited to land regions but extend over ocean regions downwind of fire sources. Net RFPs stronger than $-5 \mathrm{~W} \mathrm{~m}^{-2}$ occur over parts of the North Pacific, Tropical Pacific, and Tropical Atlantic oceans, including the stratocumulus decks off the coasts of western South America and western Africa (Fig. 6a, b). Ward et al. (2012) similarly identified strong cloud forcing associated with these stratocumulus decks. The presence of such highly inhomogeneous forcing over ocean may lead to perturbed surface temperature gradients which in turn may lead to large-scale circulation changes and precipitation impacts (Wang, 2015). However, changes 

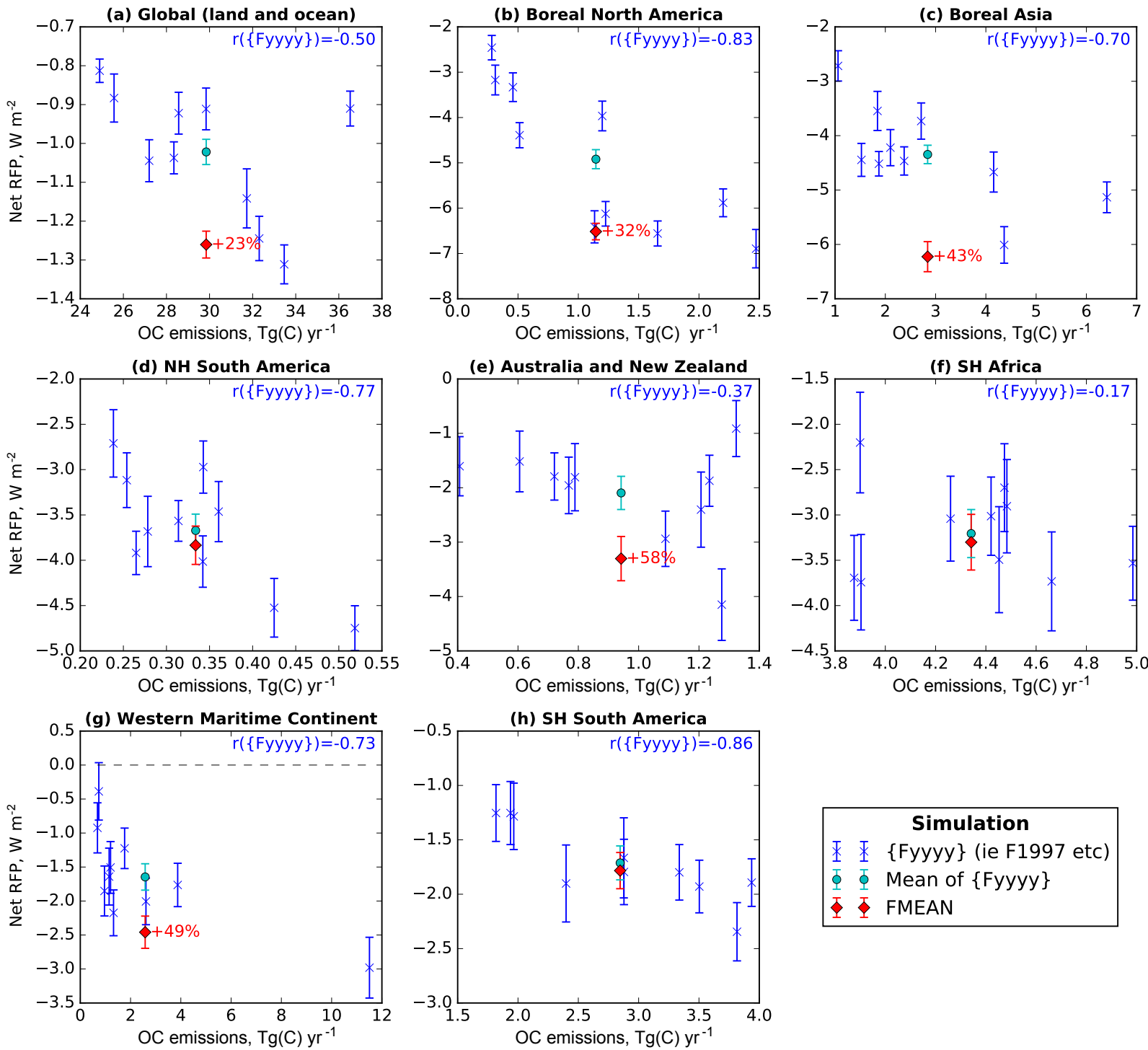

Figure 5. Net radiative flux perturbation (RFP) vs. organic carbon (OC) emissions for the globe and seven different regions. The RFPs are relative to simulation F0. Each point represents the results for a different simulation or group of simulations (in the case of the mean of \{Fyyyy\}). Error bars represent combined standard error (see Fig. 3 caption). The Pearson's product-moment correlation coefficient ( $r$ ), calculated from the 10-member \{Fyyyy ensemble (blue points), is shown in blue text at the top right of each panel. For regions where the FMEAN-\{Fyyyy $\}$ difference is statistically significant at two-tailed $p<0.05$ (tested using Welch's $t$ test, using annual mean data as the input), the FMEAN-\{Fyyyy\} percentage difference (relative to \{Fyyyy $\}$ ) is shown in red text.

in SST gradients are outside the scope of the present study, which analyses results from prescribed-SST simulations.

For the regions discussed below, negative cloud shortwave RFPs are generally associated with increases in grid-box average liquid water path and total water path (Fig. S14). Negative cloud longwave RFPs are generally associated with decreases in ice water path (Figs. S11, S14).

Organic carbon emissions are almost entirely responsible for the negative net RFPs associated with fire aerosols
(Fig. S9a). By comparison, the contributions of black carbon and sulfur dioxide are much smaller (Fig. S9b, c).

\subsubsection{Boreal North America and Boreal Asia}

Forest fires dominate the fire aerosol emissions from both Boreal North America (Fig. 2b) and Boreal Asia (Fig. 2c). These boreal regions are prone to the strongest net RFPs of any of the land regions (Table 1) and are therefore discussed first. 
(a) FMEAN-FO ("conventional")

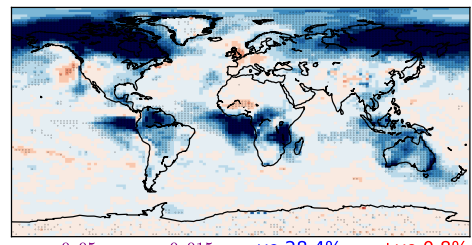

(c) FMEAN-\{Fyyyy $\}$ (difference)
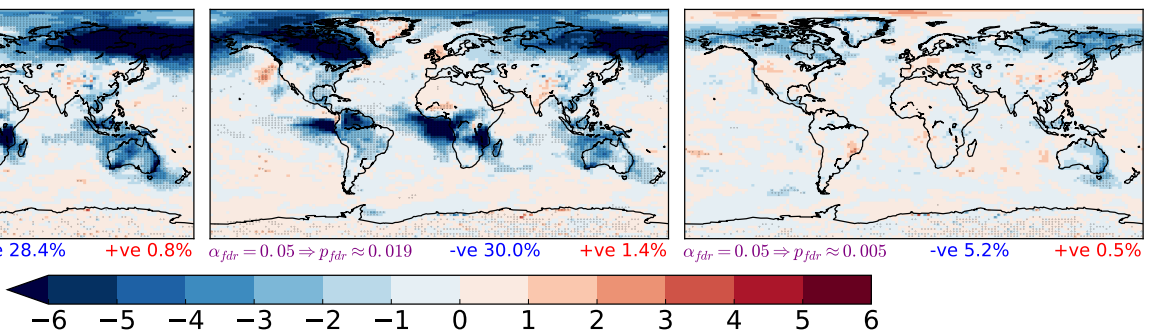

Net RFP, W m $\mathrm{m}^{-2}$

Figure 6. Net (shortwave plus longwave) top-of-atmosphere radiative flux perturbations (RFPs) for (a) simulation FMEAN relative to simulation F0, (b) the $\{$ Fyyyy $\}$ ensemble relative to simulation F0, and (c) the FMEAN-\{Fyyyy $\}$ difference. Stippling indicates differences that are statistically significant at a significance level of $\alpha_{\mathrm{fdr}}=0.05$ after controlling the false discovery rate (FDR; Benjamini and Hochberg, 1995; Wilks, 2016). The two-tailed $p$ values are generated by Welch's $t$ test, using annual mean data as the input. The approximate $p$ value threshold, $p_{\mathrm{fdr}}$, is written in purple underneath each map. The percentage of the globe (area-weighted) over which negative ( - ve) statistically significant differences occur is written in blue text underneath each map, while the percentage of the globe over which positive $(+$ ve) statistically significant differences occur is written in red text.

Boreal North America has a conventional net RFP of $-6.5 \mathrm{~W} \mathrm{~m}^{-2}$ (Table 1). This net RFP is dominated by the cloud shortwave RFP of $-5.9 \mathrm{~W} \mathrm{~m}^{-2}$ (Table 2), driven by the organic carbon emissions (Fig. 3b). As pointed out by Jiang et al. (2016), "the large cloud liquid water path over land areas of the Arctic favors the strong fire aerosol indirect effect" (Jiang et al., 2016). The next largest component is the surface albedo RFP of $-0.6 \mathrm{~W} \mathrm{~m}^{-2}$ (Table S2), driven by both organic carbon and sulfur emissions (Fig. 4b), reflecting an increase in snow cover - during the summer months of JuneAugust, the fraction of the ground covered by snow increases from $4.0 \%$ in F0 to $5.3 \%$ in FMEAN. In comparison to the surface albedo RFP, the cloud longwave RFP (Fig. 3b, Table S1) and direct effect RFP (Fig. 4b, Table S3) are much smaller.

Compared to Boreal North America, Boreal Asia has a slightly weaker conventional net RFP of $-6.2 \mathrm{~W} \mathrm{~m}^{-2}$ (Table 1). As was the case for Boreal North America, the net RFP for Boreal Asia is dominated the cloud shortwave RFP of $-5.8 \mathrm{~W} \mathrm{~m}^{-2}$ (Table 2), driven by the organic carbon emissions (Fig. 3c). The surface albedo RFP of $-0.3 \mathrm{~W} \mathrm{~m}^{-2}$ (Table S2) and cloud longwave RFP of $-0.2 \mathrm{~W} \mathrm{~m}^{-2}$ (Table S1) are also driven by the organic carbon emissions (Figs. 4c, 3c). The direct effect RFP is much smaller (Table S3).

For both boreal regions, the large interannual variability of organic carbon emissions contributes to large variability in net RFP (Fig. 5b, c). Over Boreal North America, a strong correlation of -0.83 between the annual organic carbon emissions and the net RFP demonstrates that the annual total organic carbon emissions can explain $69 \%$ of the variance in net RFP (assuming a linear relationship). F2001, which has the lowest emissions, has a net RFP of $-2.5 \mathrm{~W} \mathrm{~m}^{-2}$, while $\mathrm{F} 2004$, which has the highest emissions, has a net RFP of $-6.9 \mathrm{~W} \mathrm{~m}^{-2}$ (Figs. $2 b, 3 b, 5 b$ ). This vari- ability in the net RFP is dominated by variability in the cloud shortwave RFP (Fig. 3b).

Over Boreal Asia, a correlation of -0.70 demonstrates that the variability in the annual total organic carbon emissions can explain $49 \%$ of the variance in net RFP (Fig. 5c). F2004, which has the lowest emissions, has a net RFP of $-2.7 \mathrm{~W} \mathrm{~m}^{-2}$, while $\mathrm{F} 2003$, which has the highest emissions, has a net RFP of $-5.1 \mathrm{~W} \mathrm{~m}^{-2}$ (Figs. 2c, 3c, 5c). F1998, which has much lower emissions than F2003, has an even stronger net RFP of $-6.0 \mathrm{~W} \mathrm{~m}^{-2}$, indicating that the regional annual total emissions are not the sole determining factor of net RFP strength. This suggests that variability in timing and the specific location of the fires also plays a role, possibly due to the non-linear influence of aerosols on clouds (see Discussion).

When the interannually variability of emissions is taken into account, the revised net RFPs are significantly weaker than the conventional net RFPs over both boreal regions. Over Boreal North America, the conventional approach of ignoring interannual variability leads to a $32 \%$ overestimation of net RFP strength (Fig. 5b, Table 1) and a 33\% overestimation of cloud shortwave RFP strength (Table 2). Over Boreal Asia, the conventional approach leads to a $43 \%$ overestimation of net RFP strength (Fig. 5c, Table 1) and a $47 \%$ overestimation of cloud shortwave RFP strength (Table 2).

\subsubsection{Northern Hemisphere South America and Southern Hemisphere South America}

Both grass fires and forest fires substantially contribute to the fire aerosol emissions from both South American regions (Fig. 2d, h). After the boreal regions, Northern Hemisphere South America has the next largest conventional net RFP (Table 1). In contrast to the boreal regions, the net RFP of $-3.8 \mathrm{~W} \mathrm{~m}^{-2}$ is dominated by the cloud longwave RFP of 
$-2.6 \mathrm{~W} \mathrm{~m}^{-2}$ (Fig. 3d, Table S1), driven by the organic carbon emissions (Fig. 3d). The negative cloud longwave RFP is associated with a decrease in high cloud fraction and a decrease in ice water path (Fig. S11).

The cloud shortwave RFP of $-1.1 \mathrm{~W} \mathrm{~m}^{-2}$ (Table 2) also contributes to the net RFP over Northern Hemisphere South America. The cloud shortwave RFP is primarily driven by the organic carbon emissions (Fig. 3d). However, the black carbon emissions also drive a negative cloud shortwave RFP (Fig. 3d), possibly as a result of semi-direct effects leading to increased cloud water path (Fig. S14d) - Koch and Del Genio (2010) have previously highlighted that there are "several mechanisms by which absorbing aerosols may either increase or decrease cloud cover".

In contrast to Northern Hemisphere South America, Southern Hemisphere South America has a weaker conventional net RFP is $-1.8 \mathrm{~W} \mathrm{~m}^{-2}$ (Table 1 ), with approximately equal contributions of $-0.8 \mathrm{~W} \mathrm{~m}^{-2}$ coming from the cloud shortwave RFP (Table 2) and the cloud longwave RFP (Fig. 3h, Table S1). Both the cloud shortwave RFP and the cloud longwave RFP are primarily driven by the organic carbon emissions (Fig. 3h).

Net RFP exhibits interannual variability over both South American regions. For example, over Northern Hemisphere South America, F2006, which has the lowest emissions, has a net RFP of $-2.7 \mathrm{~W} \mathrm{~m}^{-2}$, while F2003, which has the highest emissions, has a net RFP of $-4.7 \mathrm{~W} \mathrm{~m}^{-2}$ (Figs. 2d, 3d, $5 d)$. Variability in the annual total organic carbon emissions can explain $59 \%$ of the variance in net RFP over Northern Hemisphere South America (Fig. 5d) and $74 \%$ of the variance in net RFP over Southern Hemisphere South America (Fig. 5h).

For both South American regions, the revised net RFP is comparable to the conventional net RFP (Table 1). In fact, the conventional-revised net RFP differences are statistically insignificant, indicating that the conventional approach of ignoring interannual variability does not significantly impact net RFP over either South American region. However, if the model were to include a representation of aerosol indirect effects on convective cloud microphysics, the results might be different for these convectively active tropical regions.

\subsubsection{Australia and New Zealand}

As was the case for the South American regions, both grass fires and forest fires contribute to the fire aerosol emissions from the Australia and New Zealand region (Fig. 2e). The conventional net RFP is $-3.3 \mathrm{~W} \mathrm{~m}^{-2}$ (Table 1). As was the case over the Boreal regions, the net RFP over Australia and New Zealand is dominated the cloud shortwave RFP (Table 2), driven by the organic carbon emissions (Fig. 3e). The cloud longwave RFP, surface albedo effect RFP, and direct effect RFP are all statistically insignificant (Tables S1-S3).

Only a weak correlation exists between annual total organic carbon emissions and net RFP over Australia and New
Zealand (Fig. 5e). Of the $\{$ Fyyyy $\}$ ensemble members, F2003 has the highest organic carbon emissions (Fig. 2e) yet has the weakest net RFP of $-0.9 \mathrm{~W} \mathrm{~m}^{-2}$ (Figs. 3e, 5e). F2002, which has comparable organic carbon emissions, has a much larger net RFP of $-4.1 \mathrm{~W} \mathrm{~m}^{-2}$. It is clear that the annual total emission of organic carbon is not the primary driver of interannual variability in net RFP over Australia and New Zealand.

The revised net RFP of $-2.1 \mathrm{~W} \mathrm{~m}^{-2}$ is significantly weaker that the conventional net RFP of $-3.3 \mathrm{~W} \mathrm{~m}^{-2}$ (Table 1). The conventional approach overestimates the strength of net RFP by $58 \%$ (Fig. 5e), the largest percentage difference found for any of the regions discussed in this section.

\subsubsection{Southern Hemisphere Africa}

In contrast to all the regions discussed above, the fire aerosol emissions from Southern Hemisphere Africa are almost completely driven by grass fires (Fig. 2f). The conventional net RFP is $-3.3 \mathrm{~W} \mathrm{~m}^{-2}$ (Table 1). The cloud shortwave RFP of $-2.0 \mathrm{~W} \mathrm{~m}^{-2}$ (Table 2) and the cloud longwave RFP of $-1.4 \mathrm{~W} \mathrm{~m}^{-2}$ (Table $\mathrm{S} 1$ ) are both driven by the organic carbon emissions (Fig. 3f).

Net RFP ranges from $-2.2 \mathrm{~W} \mathrm{~m}^{-2}$ in $\mathrm{F} 1999$ to $-3.7 \mathrm{~W} \mathrm{~m}^{-2}$ in F1997, F2000, and F2005 (Fig. 3f). The correlation between annual total organic carbon emissions and net RFP is very weak (Fig. 5f). Variability in the annual total organic carbon emissions can explain less than $3 \%$ of the variance in net RFP. Other factors, such as the specific timing and location of emissions, must drive the interannual variability in net RFP.

The revised net RFP of $-3.2 \mathrm{~W} \mathrm{~m}^{-2}$ is comparable to the conventional net RFP of $-3.3 \mathrm{~W} \mathrm{~m}^{-2}$ (Table 1). The difference is statistically insignificant. This indicates that the conventional approach does not significantly impact net RFP over Southern Hemisphere Africa.

\subsubsection{Western Maritime Continent}

Forest fires dominate the fire aerosol emissions from the Western Maritime Continent (Fig. 2g). The conventional net RFP is $-2.5 \mathrm{~W} \mathrm{~m}^{-2}$ (Table 1). In contrast to the regions discussed above, with the exception of Northern Hemisphere South America, the net RFP is dominated by the cloud longwave RFP of $-1.7 \mathrm{~W} \mathrm{~m}^{-2}$ (Fig. 3g, Table S1), driven by the organic carbon emissions (Fig. 3g). The cloud shortwave RFP is actually statistically insignificant (Table 2).

A relatively strong correlation exists between annual organic carbon emissions and net RFP, with variability in annual organic carbon emissions able to explain $53 \%$ of the variance in net RFP (Fig. 5g). One outlier likely contributes disproportionately to the correlation: F1997 has by far the highest fire aerosol emissions (Fig. 2g) also has the largest net RFP of $-3.0 \mathrm{~W} \mathrm{~m}^{-2}$ (Fig. 3g). Among the other \{Fyyyy ensemble members, the net RFP varies between -0.4 and 
$-2.2 \mathrm{~W} \mathrm{~m}^{-2}$. The relationship between organic carbon emissions and net RFP appears to be non-linear (Fig. 5g).

The revised net RFP of $-1.6 \mathrm{~W} \mathrm{~m}^{-2}$ is significantly weaker that the conventional net RFP of $-2.5 \mathrm{~W} \mathrm{~m}^{-2}$ (Table 1). The conventional approach overestimates the strength of net RFP by $49 \%$ (Fig. $5 \mathrm{~g}$ ). Interestingly, although the net RFP is dominated by the cloud longwave RFP, the conventional-revised difference in cloud longwave RFP is relatively small $\left(-0.2 \mathrm{~W} \mathrm{~m}^{-2}\right)$ and statistically insignificant (Table S1). The conventional-revised difference in cloud shortwave RFP is larger $\left(-0.6 \mathrm{~W} \mathrm{~m}^{-2}\right)$, although this is also statistically insignificant (Table 2). These statistically insignificant differences in cloud longwave RFP and cloud shortwave RFP combine to form a statistically significant difference in net RFP.

\subsubsection{Other land regions}

Six of the other eight land regions have statistically significant conventional net RFPs ranging from $-0.6 \mathrm{~W} \mathrm{~m}^{-2}$ to $-1.6 \mathrm{~W} \mathrm{~m}^{-2}$ (Table 1). The conventional approach leads to a statistically significant overestimation of the strength of the net RFP over only two of these six regions: Central America and Southeast Asia (Table 1).

\subsection{The hydrological fast response}

In addition to facilitating the calculation of RFPs, the prescribed-SST simulations analysed in this paper facilitate investigation of the hydrological fast response (Bala et al., 2010). The hydrological fast response to the fire aerosols is discussed here; investigation of the hydrological slow response, which depends on the ocean response, may be investigated in future work.

CAM5, in common with most global climate models, diagnoses two categories of precipitation: the component that is diagnosed by the convection scheme is referred to as "convective precipitation", while the component that is diagnosed by the large-scale stratiform cloud scheme is referred to as "large-scale precipitation". We refer to the sum of these two components as the total precipitation.

Globally, the fire aerosols suppress total precipitation by $2 \mathrm{~mm}_{\text {year }}{ }^{-1}$ on average (Table 3 ). The convective and largescale components are both suppressed by approximately $1 \mathrm{~mm}$ year $^{-1}$ (Fig. 7a). Although black carbon and sulfur dioxide were found to make only a small contribution to the net RFP of the fire aerosols, these two species play a major role in the global hydrological fast response to fire aerosols: black carbon and sulfur dioxide, rather than organic carbon, contribute to the suppression of convective precipitation, and black carbon exerts the strongest suppression of large-scale precipitation (Fig. 7a). It is difficult to interpret the mechanisms behind these global mean features, due to spatial inhomogeneity in the regional response (see below).
Regionally, the strongest suppression of total precipitation by black carbon occurs over the western tropical Pacific Ocean (Fig. S10b), with the caveat that statistical significance is absent. In contrast, organic carbon often plays a more important role in the hydrological fast response over many land regions (Figs. S10a and 7b-h). For example, our results suggest that a strong suppression of precipitation over Southern Hemisphere Africa is primarily driven by organic carbon emissions (Fig. 7f), in contrast to the conclusions of Hodnebrog et al. (2016), who suggest that black carbon also plays an important role.

For all seven regions shown in Fig. 7, the organic carbon emissions suppress both total precipitation and convective precipitation. The organic carbon emissions also suppress large-scale precipitation over five of the regions (Fig. 7d-h). The exceptions are the two boreal regions where, although total precipitation is suppressed, large-scale precipitation is actually enhanced slightly by the fire aerosols (Fig. 7b-c). This enhancement of large-scale precipitation over the boreal regions partially offsets the much stronger suppression of convective precipitation.

Using interannually invariant fire emissions does not significantly affect the hydrological fast response of total precipitation either globally or over any of the regions, as shown by the lack of statistically significant conventional-revised differences in Table 3 and Fig. 8c. However, if an interactive ocean model were to be used, the conventional-revised RFP differences would likely impact SSTs which in turn would likely impact the hydrological slow response.

\section{Discussion: how do the effects of interannually varying emissions differ from those of interannually invariant climatological emissions?}

Most global climate modelling studies use interannually invariant emissions of fire aerosols. In this study, the FMEAN simulation also followed this conventional approach of ignoring interannual variability. In contrast, the $\{$ Fyyyy $\}$ ensemble facilitates calculation of revised RFPs that take into account the interannual variability of the emissions. Consideration of conventional-revised RFP differences reveals the impact of the conventional approach of ignoring interannual variability of emissions.

Globally, the conventional approach causes net RFP strength to be overestimated by $23 \%$ (Table 1, Fig. 5a). Over 6 of the 15 regions (Fig. 1), the conventional approach also causes net RFP strength to be statistically significantly overestimated (Table 1). Over Australia and New Zealand, the overestimation is as large as $58 \%$ (Fig. 5e). Over Boreal Asia, an overestimation of $43 \%$ (Fig. 5c) corresponds to a conventional-revised RFP difference of $-1.9 \mathrm{~W} \mathrm{~m}^{-2}$ (Table 1).

When the net conventional-revised net RFP differences are calculated at the model output resolution of $1.9^{\circ} \times 2.5^{\circ}$, 
Table 3. Total (large-scale plus convective) annual precipitation differences for different simulation combinations and regions. Combined standard errors have been calculated. Significance has been tested using Welch's $t$ test: ${ }^{\text {a }}$ indicates differences that are statistically significant at two-tailed $p<0.05$, and ${ }^{\mathrm{b}}$ indicates differences that are statistically significant at two-tailed $p<0.01$.

\begin{tabular}{lrrr}
\hline \multirow{2}{*}{ Region } & \multicolumn{3}{c}{ Total precipitation difference, $\mathrm{mm} \mathrm{yr}^{-1}$} \\
\cline { 2 - 4 } & $\begin{array}{r}\text { FMEAN-F0 } \\
\text { conventional }\end{array}$ & $\begin{array}{r}\text { Fyyyy }-F 0 \\
\text { revised }\end{array}$ & $\begin{array}{r}\text { FMEAN-\{Fyyyy }\} \\
\text { difference }\end{array}$ \\
\hline Global (land and ocean) & $-2.1 \pm 0.4^{\mathrm{b}}$ & $-2.0 \pm 0.4^{\mathrm{b}}$ & $-0.1 \pm 0.4$ \\
\hline Boreal North America & $-11.8 \pm 3.6^{\mathrm{b}}$ & $-14.1 \pm 3.4^{\mathrm{b}}$ & $+2.3 \pm 2.7$ \\
Boreal Asia & $-22.7 \pm 3.5^{\mathrm{b}}$ & $-18.5 \pm 2.9^{\mathrm{b}}$ & $-4.2 \pm 3.0$ \\
NH South America & $-102.1 \pm 15.1^{\mathrm{b}}$ & $-85.0 \pm 12.1^{\mathrm{b}}$ & $-17.1 \pm 12.5$ \\
Australia and New Zealand & $-34.8 \pm 15.1^{\mathrm{a}}$ & $-49.2 \pm 11.3^{\mathrm{b}}$ & $+14.4 \pm 13.2$ \\
SH Africa & $-38.5 \pm 8.2^{\mathrm{b}}$ & $-50.5 \pm 6.5^{\mathrm{b}}$ & $+12.0 \pm 7.2$ \\
Western Maritime Continent & $-39.1 \pm 21.7$ & $-58.5 \pm 18.4^{\mathrm{b}}$ & $+19.4 \pm 18.2$ \\
SH South America & $-33.9 \pm 5.2^{\mathrm{b}}$ & $-26.5 \pm 4.8^{\mathrm{b}}$ & $-7.4 \pm 4.1$ \\
\hline Central America & $+19.5 \pm 10.6$ & $+12.0 \pm 9.1$ & $+7.5 \pm 8.4$ \\
Eastern Maritime Continent & $-6.5 \pm 16.4$ & $-2.6 \pm 14.6$ & $-3.9 \pm 13.0$ \\
Temperate North America & $-2.5 \pm 8.7$ & $+7.7 \pm 7.7$ & $-10.1 \pm 6.5$ \\
Central Asia & $-6.3 \pm 5.1$ & $-2.9 \pm 4.2$ & $-3.4 \pm 4.1$ \\
NH Africa & $-31.9 \pm 10.0^{\mathrm{b}}$ & $-33.1 \pm 7.9^{\mathrm{b}}$ & $+1.2 \pm 8.0$ \\
Southeast Asia & $-12.5 \pm 14.0$ & $-18.3 \pm 10.9$ & $+5.8 \pm 11.9$ \\
Europe & $-6.5 \pm 5.7$ & $-5.0 \pm 4.4$ & $-1.5 \pm 4.7$ \\
Middle East & $+8.4 \pm 5.5$ & $+3.0 \pm 4.0$ & $+5.3 \pm 4.6$ \\
\hline
\end{tabular}

statistically significant negative differences occur across $5.2 \%$ of the globe by area after controlling the false discovery rate (Benjamini and Hochberg, 1995; Wilks, 2016) (Fig. 6c). In contrast, statistically significant positive differences occur across only $0.5 \%$ of the globe. There is no clear signal of positive conventional-revised differences. Hence, there is no clear evidence that the conventional approach of ignoring interannual variability ever leads to an underestimation of the net RFP strength. Rather, for some regions, the conventional approach leads to a systematic overestimation of net RFP strength (Fig. 6c, Table 1), dominated by an overestimation of the cloud shortwave RFP strength (Table 2).

We hypothesize that the overestimation of cloud shortwave RFP strength occurs due to the non-linear influence of aerosols on clouds. For example, there is evidence of a "sublinear dependence of cloud droplet concentrations on aerosol number" (Stevens and Feingold, 2009). At high concentration levels, the aerosol indirect effects may saturate. Therefore, compared to using interannually varying emissions, spreading out the aerosol emissions in time by averaging across different years will likely lead to a stronger indirect effect on average.

In order to test this hypothesis, we have produced scatter plots of cloud shortwave RFP vs. surface organic carbon aerosol concentration for different months and locations within the Boreal Asia region (Fig. 9). Boreal Asia has been chosen because it is the region with the largest conventionalrevised difference in cloud shortwave RFP (Table 2). The first location-month combination (Fig. 9a) has been selected because it is the location-month combination with the largest conventional-revised cloud shortwave RFP difference. The second location-month combination (Fig. 9b) is the combination with the next largest difference, with the additional criterion that the location is at least $10^{\circ}$ (either longitude or latitude) from the previously selected location (Fig. 9a) so as to sample more widely geographically. Similarly, the third, fourth, and fifth combinations (Fig. 9c-e) are those with the next largest differences at locations at least $10^{\circ}$ from any of the previously selected locations. The method for selecting these five location-month combinations is shown in Fig. S12.

Looking at the scatter plots of cloud shortwave RFP vs. surface organic carbon aerosol concentration (Fig. 9), the following observations can be made.

1. For all five location-month combinations, the surface organic carbon aerosol concentration is very similar between the conventional and revised approaches. On a larger scale, no significant conventional-revised difference in surface organic carbon aerosol concentration is found for either the globe or any of the 15 regions (Table S4). This suggests that conventional-revised differences in cloud shortwave RFP are not driven by differences in aerosol lifetime (for further discussion on how fire episodicity may impact aerosol lifetime, see Clark et al., 2015).

2. For three of the location-month combinations (Fig. 9ac), a non-linear relationship between surface organic 

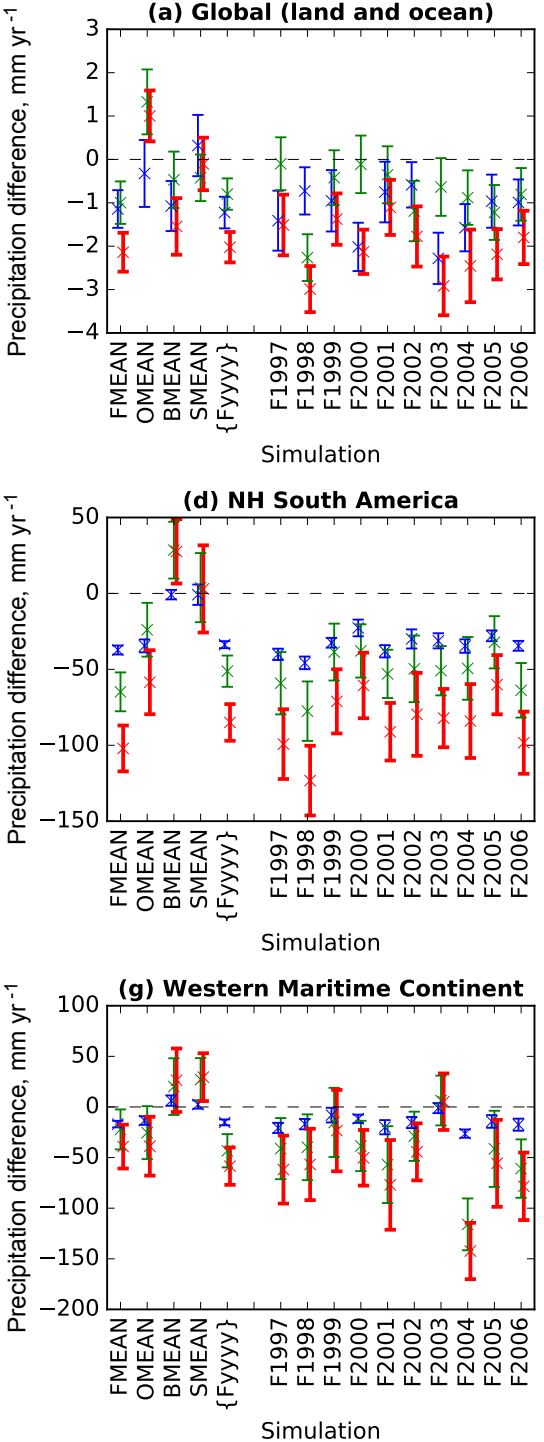

(b) Boreal North America

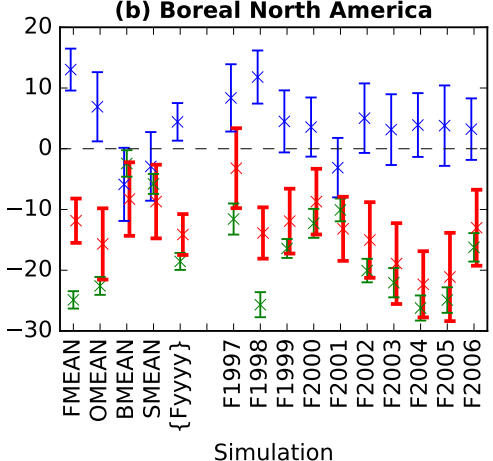

(e) Australia and New Zealand

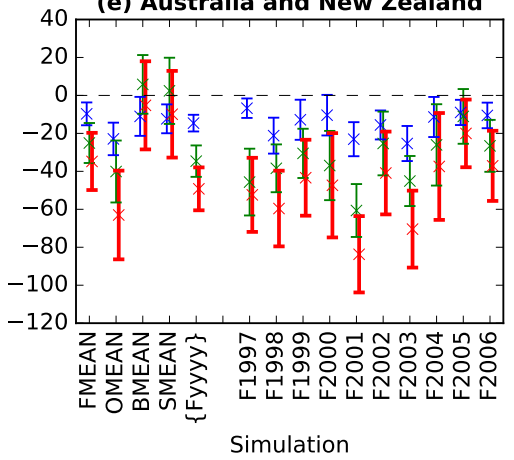

(h) SH South America

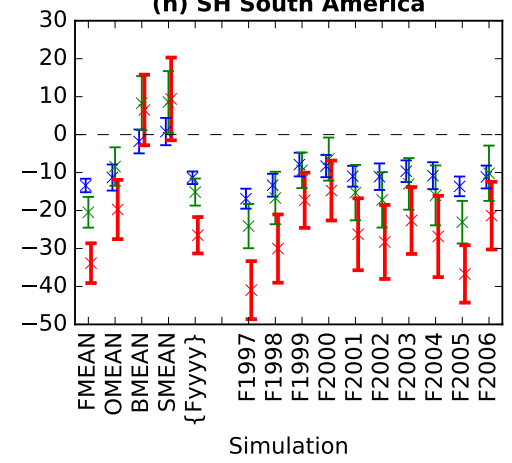

(c) Boreal Asia

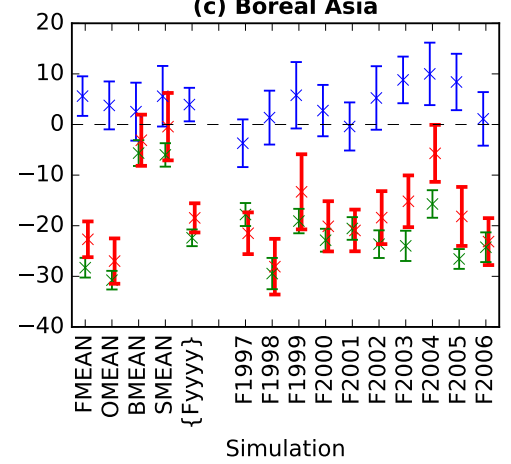

(f) SH Africa

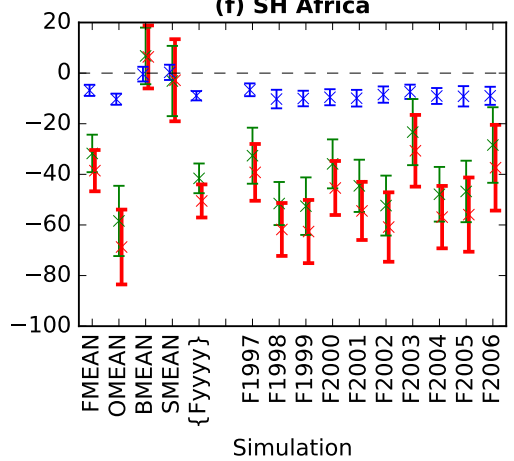

Precipitation difference
来 Large-scale precipitation
来 全 Convective precipitation
I I Total preciptation

Figure 7. Large-scale, convective, and total (large-scale plus convective) annual precipitation differences, relative to simulation F0, for the globe and seven regions. Error bars represent combined standard error. Results for another eight regions are shown in Fig. S8.

carbon aerosol concentration and cloud shortwave RFP is evident. A logarithmic fit works well, with the cloud shortwave RFP scaling approximately linearly with the logarithm of the surface organic carbon aerosol concentration. The nature of the logarithmic relationship causes the mean of the $\{$ Fyyyy $\}$ ensemble to have a weaker cloud shortwave RFP than an individual \{Fyyyy ensemble member with a similar surface organic carbon aerosol concentration, an effect that is particularly evident in Fig. 9a, c. The remaining two location-month combinations (Fig. 9d, e) do not exhibit a clear relationship between surface organic carbon aerosol concentration and cloud shortwave RFP. For these two location-month combinations, the surface or- ganic carbon aerosol concentration is not a good predictor of cloud shortwave RFP, possibly because surface organic carbon aerosol concentration may not always be a good proxy for the cloud condensation nuclei available to clouds.

3. For one of the location-month combinations (Fig. 9c), the cloud shortwave RFP for the FMEAN simulation is very similar to that of the $\{$ Fyyyy $\}$ ensemble member that has a similar surface organic carbon aerosol concentration. For this location-month combination, it appears that the non-linear relationship between surface organic carbon aerosol concentration and cloud shortwave RFP can explain most of the large conventional- 


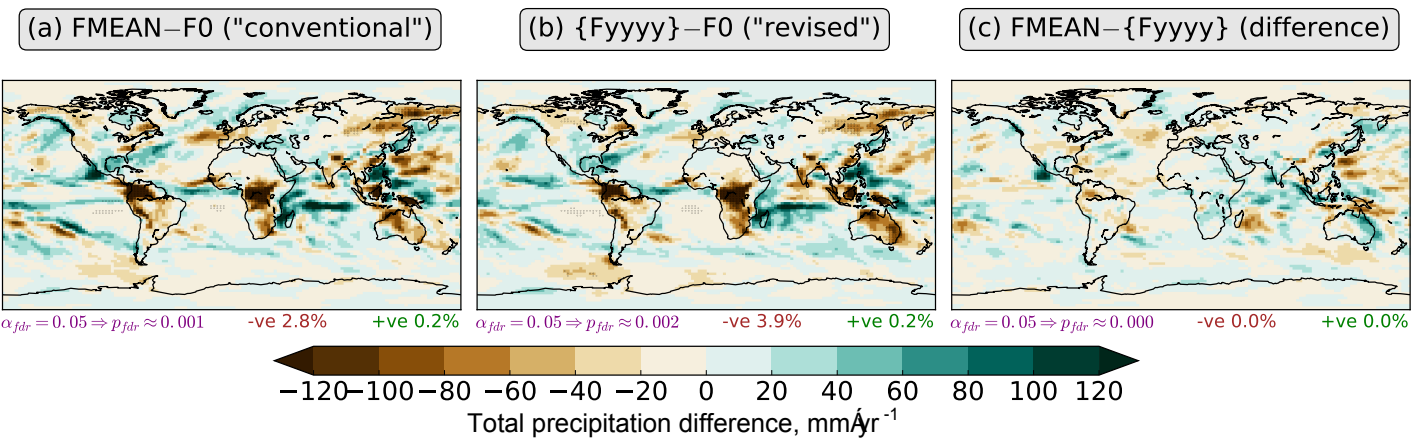

Figure 8. Total (large-scale plus convective) annual precipitation differences for (a) simulation FMEAN relative to simulation F0, (b) the \{Fyyyy ensemble relative to simulation F0, and (c) the FMEAN-\{Fyyyy difference. Stippling indicates differences that are statistically significant at a significance level of $\alpha_{f d r}=0.05$ after controlling the false discovery rate (FDR; Benjamini and Hochberg, 1995; Wilks, 2016). The two-tailed $p$ values are generated by Welch's $t$ test, using annual mean data as the input. The approximate $p$ value threshold, $p_{\mathrm{fdr}}$, is written in purple underneath each map. The percentage of the globe (area-weighted) over which negative ( - ve) statistically significant differences occur is written in brown text underneath each map, while the percentage of the globe over which positive (+ve) statistically significant differences occur is written in green text.

revised difference in cloud shortwave RFP. This supports our hypothesis that the conventional overestimation of cloud shortwave RFP strength occurs due to the non-linear influence of aerosols on clouds. The interpretation is less clear in Fig. 9a, b, where the FMEAN cloud shortwave RFP is stronger than would be expected for the given surface organic carbon aerosol concentration.

It is worth noting that the results presented in Fig. 9 have two obvious limitations. First, as pointed out above, surface organic carbon aerosol concentration may not always be a good proxy for the cloud condensation nuclei available to clouds. Second, these results may not apply generally to the Boreal Asia region because they represent only a relatively small sample of location-month combinations, selected because they have large conventional-revised differences.

In order to partially address the second of these limitations, corresponding results showing cloud shortwave RFP vs. surface organic carbon aerosol concentration averaged across the whole Boreal Asia region during July and August are shown in Fig. S13. The first two observations about Fig. 9 listed above also apply to the Boreal Asia regional averages shown in Fig. S13: the surface organic carbon aerosol concentration is very similar between the conventional and revised approaches, and a logarithmic fit works well, with the cloud shortwave RFP scaling approximately linearly with the logarithm of the surface organic carbon aerosol concentration. However, the conventional approach still produces stronger cloud shortwave RFPs than would be expected from the regional average organic carbon aerosol concentrations, although this may be primarily due to the fact that the use of regional averages obscures differing spatial inhomogeneities in surface organic carbon aerosol concentration.

Figures 9 (especially panel c) and S13 provide some evidence in support of our hypothesis that the overestimation of cloud shortwave RFP strength occurs due to the non-linear influence of aerosols on clouds. In order to test this hypothesis more conclusively, it would be advantageous to perform idealized simulations designed to isolate the contribution of different aerosol sources, aerosol species, and aerosol effects. Such further analysis is outside the scope of the present study.

Despite the impact on net RFP, using interannually invariant emissions does not significantly impact the hydrological fast response, as shown by the absence of statistically significant conventional-revised differences in Table 3 and Fig. 8c. The prescribed-SST simulations analysed here do not facilitate analysis of the hydrological slow response. However, if SST feedbacks were to be included, the conventionalrevised RFP differences would likely impact surface temperature gradients. Changes in surface temperature gradients are known to impact precipitation patterns (Wang, 2015). Hence, it is foreseeable that the conventional approach of ignoring interannual variability might influence the hydrological slow response.

\section{Conclusions}

In this study, we have investigated the radiative effects of interannually varying emissions of fire aerosols. Our prescribed-SST CAM5 simulation results suggest that fire aerosols exert a net radiative effect of $-1.0 \mathrm{~W} \mathrm{~m}^{-2}$ on the climate system. This net radiative effect is dominated by the cloud shortwave response to organic carbon emissions. Boreal regions are especially susceptible. For example, over Boreal North America, the net radiative effect of the fire aerosols is $-4.9 \mathrm{~W} \mathrm{~m}^{-2}$ on average, ranging from -2.5 to $-6.9 \mathrm{~W} \mathrm{~m}^{-2}$ in different years. 

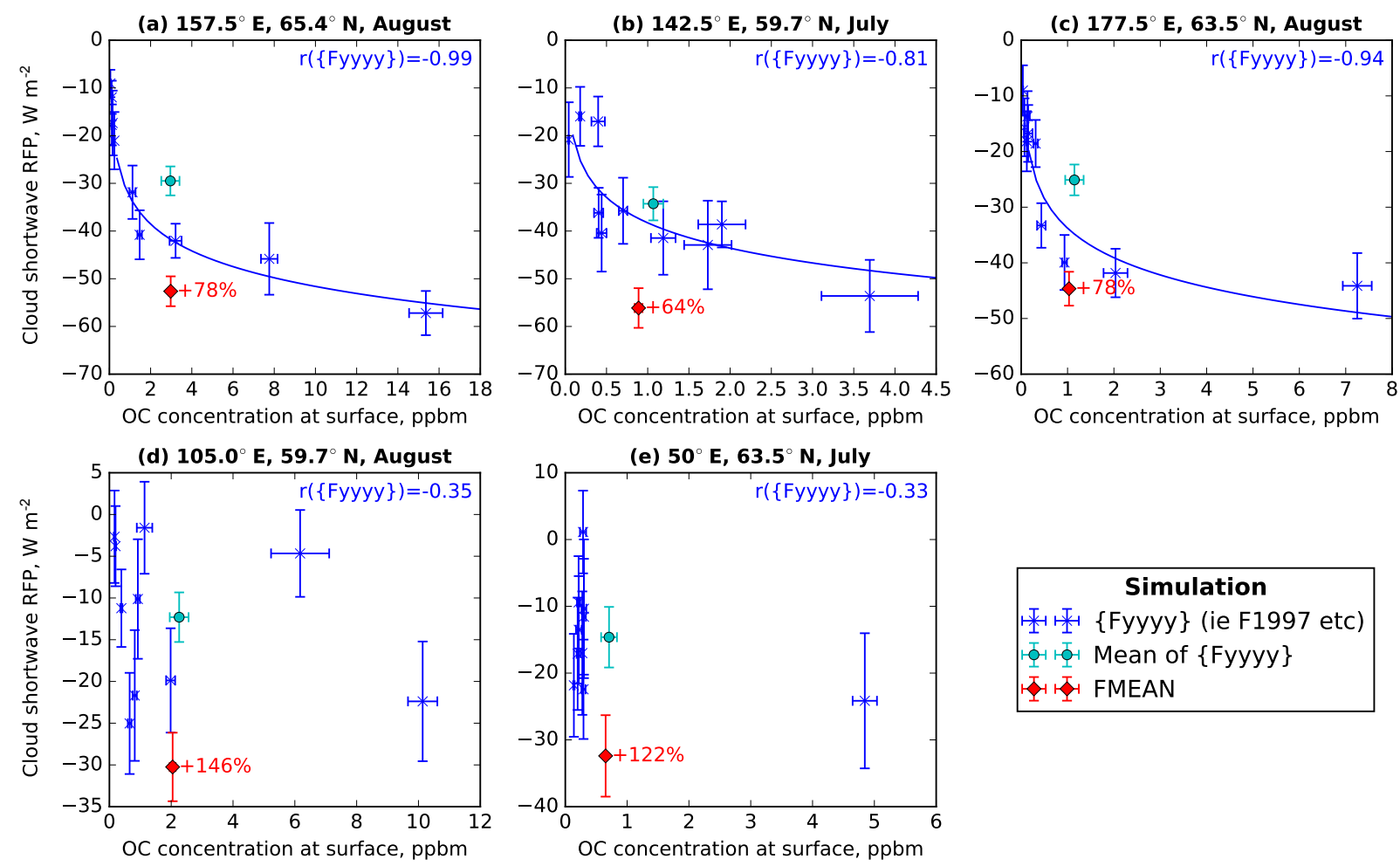

Figure 9. Cloud shortwave top-of-atmosphere radiative flux perturbation (RFP) vs. surface organic carbon (OC) aerosol concentration for different months and locations within the Boreal Asia region. The five location-month combinations have been selected according to the procedure described in Fig. S12, based on the following three criteria: (1) within the Boreal Asia region, select the location-month combinations with (2) the largest FMEAN-\{Fyyyy cloud shortwave RFP differences, (3) at least $10^{\circ}$ (either longitude or latitude) from one another. The RFPs are relative to simulation F0. The organic carbon aerosol concentrations are given in parts-per-billion by mass $\left(1 \mathrm{ppbm}=10^{-9} \mathrm{~kg} \mathrm{~kg}^{-1}\right)$. Each point represents the results for a different simulation or group of simulations (in the case of the mean of $\{$ Fyyyy\}). Error bars represent combined standard error (see Fig. 3 caption). In (a-c), the blue line shows the results of a linear regression fit to $y=a+b \ln x$, calculated from the 10-member \{Fyyyy ensemble (blue points). In both (d, e), the regression fit was found to be statistically insignificant at the $\alpha=0.05$ significance level and is therefore not shown. The corresponding Pearson's product-moment correlation coefficient $(r)$ for $y=a+b \ln x$, calculated from the 10-member \{Fyyyy\} ensemble, is shown in blue text at the top right of each panel. For regions where the FMEAN-\{Fyyyy\} difference is statistically significant at two-tailed $p<0.05$ (tested using Welch's $t$ test, using annual mean data as the input), the FMEAN-\{Fyyyy percentage difference (relative to $\{$ Fyyyy $\}$ ) is shown in red text.

Conventionally, a monthly climatology of emissions of fire aerosols has often been used to drive global climate models. This conventional approach of ignoring the interannual variability of the emissions can lead to a significant overestimation of the net radiative effect of the fire aerosols. Compared to our revised approach of using interannually varying emissions, the conventional approach of ignoring interannual variability can lead to a $+23 \%$ overestimation of the global mean net radiative effect. For some regions, the conventional approach leads to an even larger overestimation of the strength of the net radiative effect of the fire aerosols: $+32 \%\left(-1.6 \mathrm{~W} \mathrm{~m}^{-2}\right)$ over Boreal North America, $+43 \%$ $\left(-1.9 \mathrm{~W} \mathrm{~m}^{-2}\right)$ over Boreal Asia, $+58 \%\left(-1.2 \mathrm{~W} \mathrm{~m}^{-2}\right)$ over Australia and New Zealand, and $+49 \%\left(-0.8 \mathrm{~W} \mathrm{~m}^{-2}\right)$ over the Western Maritime Continent.
There is evidence to suggest that the overestimation associated with the conventional approach arises due to the non-linear influence of aerosols on clouds. Compared to using interannually varying emissions (our revised approach), spreading out the aerosol emissions in time by averaging across different years (the conventional approach) will likely lead to a stronger indirect effect on average.

Following the findings presented in this paper, we suggest three avenues for further research. First, similar simulations could be performed using other aerosol-climate models in order to test whether the conclusions of this study apply more generally if different parameterizations of aerosol indirect effects are used. Second, idealized simulations could be performed to improve understanding of the saturation of aerosol indirect effects. Third, coupled atmosphere-ocean simulations could be performed to investigate the impact of 
interannually varying emissions on the hydrological slow response, and other components of the climate system, including modes of climate variability.

Fire aerosols play an important role in the climate system, exerting large radiative effects regionally. In order to improve understanding of the climate system, we need to more accurately quantify these radiative effects, including critical characteristics such as seasonality and interannual variability.

\section{Data availability}

The CESM-CAM5 data analysed in this manuscript are available via Figshare: doi:10.6084/m9.figshare.3497705 (Grandey, 2016).

\section{The Supplement related to this article is available online at doi:10.5194/acp-16-14495-2016-supplement.}

Author contributions. Benjamin S. Grandey designed the experiment, performed the simulations, analysed the data, and wrote the manuscript. Hsiang-He Lee and Chien Wang contributed to the experimental design, analysis methodology, and redrafting of the manuscript.

Acknowledgements. This research was supported by the National Research Foundation (NRF), Prime Minister's Office, Singapore under its Campus for Research Excellence and Technological Enterprise (CREATE) programme. The Center for Environmental Sensing and Modeling (CENSAM) is an interdisciplinary research group (IRG) of the Singapore-MIT Alliance for Research and Technology (SMART) centre. This research was also supported by the U.S. National Science Foundation (AGS-1339264), US DOE (DE-FG02-94ER61937), and US EPA (XA-83600001-1). The CESM project is supported by the US National Science Foundation and the Office of Science (BER) of the US Department of Energy. The GFED 4.0s dry matter emission data and emissions factors were downloaded from http://www.globalfiredata.org. We would like to thank D. S. Ward and A. Veira, the two referees, for their constructive comments which have led to substantial improvement of the paper.

Edited by: S. Kloster

Reviewed by: A. Veira and D. S. Ward

\section{References}

Ackerman, A. S., Toon, O. B., Stevens, D. E., Heymsfield, A. J., Ramanathan, V., and Welton, E. J.: Reduction of Tropical Cloudiness by Soot, Science, 288, 1042-1047, doi:10.1126/science.288.5468.1042, 2000.
Albrecht, B. A.: Aerosols, cloud microphysics, and fractional cloudiness, Science, 245, 1227-30, doi:10.1126/science.245.4923.1227, 1989.

Andreae, M. O., Rosenfeld, D., Artaxo, P., Costa, A. A., Frank, G. P., Longo, K. M., and Silva-Dias, M. A. F.: Smoking rain clouds over the Amazon, Science, 303, 1337-42, doi:10.1126/science.1092779, 2004.

Bala, G., Caldeira, K., and Nemani, R.: Fast versus slow response in climate change: implications for the global hydrological cycle, Clim. Dynam., 35, 423-434, doi:10.1007/s00382-009-0583y, 2010.

Benjamini, Y. and Hochberg, Y.: Controlling the False Discovery Rate: A Practical and Powerful Approach to Multiple Testing, J. R. Stat. Soc. B, 57, 289-300, 1995.

Bollasina, M. A., Ming, Y., and Ramaswamy, V.: Anthropogenic Aerosols and the Weakening of the South Asian Summer Monsoon, Science, 334, 502-505, doi:10.1126/science.1204994, 2011.

Chuang, C. C., Penner, J. E., Prospero, J. M., Grant, K. E., Rau, G. H., and Kawamoto, K.: Cloud susceptibility and the first aerosol indirect forcing: Sensitivity to black carbon and aerosol concentrations, J. Geophys. Res., 107, 4564, doi:10.1029/2000JD000215, 2002.

Chung, C. E., Ramanathan, V., and Kiehl, J. T.: Effects of the South Asian Absorbing Haze on the Northeast Monsoon and Surface-Air Heat Exchange, J. Climate, 15, 2462-2476, doi:10.1175/1520-0442(2002)015<2462:EOTSAA>2.0.CO;2, 2002.

Clark, S. K., Ward, D. S., and Mahowald, N. M.: The sensitivity of global climate to the episodicity of fire aerosol emissions, J. Geophys. Res.-Atmos., 120, 11589-11607, doi:10.1002/2015JD024068, 2015.

Cohen, J. B. and Wang, C.: Estimating global black carbon emissions using a top-down Kalman Filter approach, J. Geophys. Res.-Atmos., 119, 307-323, doi:10.1002/2013JD019912, 2014.

Dentener, F., Kinne, S., Bond, T., Boucher, O., Cofala, J., Generoso, S., Ginoux, P., Gong, S., Hoelzemann, J. J., Ito, A., Marelli, L., Penner, J. E., Putaud, J.-P., Textor, C., Schulz, M., van der Werf, G. R., and Wilson, J.: Emissions of primary aerosol and precursor gases in the years 2000 and 1750 prescribed data-sets for AeroCom, Atmos. Chem. Phys., 6, 4321-4344, doi:10.5194/acp-64321-2006, 2006.

Feng, N. and Christopher, S. A.: Clear sky direct radiative effects of aerosols over Southeast Asia based on satellite observations and radiative transfer calculations, Remote Sens. Environ., 152, 333-344, doi:10.1016/j.rse.2014.07.006, 2014.

Gettelman, A., Liu, X., Ghan, S. J., Morrison, H., Park, S., Conley, A. J., Klein, S. A., Boyle, J., Mitchell, D. L., and Li, J.-L. F.: Global simulations of ice nucleation and ice supersaturation with an improved cloud scheme in the Community Atmosphere Model, J. Geophys. Res., 115, D18216, doi:10.1029/2009JD013797, 2010.

Gettelman, A., Liu, X., Barahona, D., Lohmann, U., and Chen, C.: Climate impacts of ice nucleation, J. Geophys. Res., 117, D20201, doi:10.1029/2012JD017950, 2012.

Ghan, S. J.: Technical Note: Estimating aerosol effects on cloud radiative forcing, Atmos. Chem. Phys., 13, 9971-9974, doi:10.5194/acp-13-9971-2013, 2013. 
Ghan, S. J., Liu, X., Easter, R. C., Zaveri, R., Rasch, P. J., Yoon, J.H., and Eaton, B.: Toward a Minimal Representation of Aerosols in Climate Models: Comparative Decomposition of Aerosol Direct, Semidirect, and Indirect Radiative Forcing, J. Climate, 25, 6461-6476, doi:10.1175/JCLI-D-11-00650.1, 2012.

Grandey, B. S.: Data for "Radiative effects of inter-annually varying vs. inter-annually invariant aerosol emissions from fires", doi:10.6084/m9.figshare.3497705, 2016.

Grandey, B. S., Cheng, H., and Wang, C.: Transient Climate Impacts for Scenarios of Aerosol Emissions from Asia: A Story of Coal versus Gas, J. Climate, 29, 2849-2867, doi:10.1175/JCLI-D-150555.1, 2016.

Haywood, J. and Boucher, O.: Estimates of the direct and indirect radiative forcing due to tropospheric aerosols: A review, Rev. Geophys., 38, 513-543, doi:10.1029/1999RG000078, 2000.

Haywood, J., Donner, L., Jones, A., and Golaz, J.-C.: Global Indirect Radiative Forcing Caused by Aerosols: IPCC (2007) and Beyond, in: Clouds in the Perturbed Climate System: Their Relationship to Energy Balance, Atmospheric Dynamics, and Precipitation, edited by: Heintzenberg, J. and Charlson, R., MIT Press, 2009.

Hodnebrog, Ø., Myhre, G., Forster, P. M., Sillmann, J., and Samset, B. H.: Local biomass burning is a dominant cause of the observed precipitation reduction in southern Africa, Nat. Commun., 7, 11236, doi:10.1038/ncomms11236, 2016.

Jacobson, M. Z.: Effects of biomass burning on climate, accounting for heat and moisture fluxes, black and brown carbon, and cloud absorption effects, J. Geophys. Res.-Atmos., 119, 89809002, doi:10.1002/2014JD021861, 2014.

Jeong, G.-R. and Wang, C.: Climate effects of seasonally varying Biomass Burning emitted Carbonaceous Aerosols (BBCA), Atmos. Chem. Phys., 10, 8373-8389, doi:10.5194/acp-10-83732010, 2010.

Jiang, Y., Lu, Z., Liu, X., Qian, Y., Zhang, K., Wang, Y., and Yang, X.-Q.: Impacts of Global Wildfire Aerosols on Direct Radiative, Cloud and Surface-Albedo Forcings Simulated with CAM5, Atmos. Chem. Phys. Discuss., doi:10.5194/acp-2016-167, in review, 2016.

Jones, A., Haywood, J. M., and Boucher, O.: Aerosol forcing, climate response and climate sensitivity in the Hadley Centre climate model, J. Geophys. Res., 112, D20211, doi:10.1029/2007JD008688, 2007.

Kaiser, J. W., Heil, A., Andreae, M. O., Benedetti, A., Chubarova, N., Jones, L., Morcrette, J.-J., Razinger, M., Schultz, M. G., Suttie, M., and van der Werf, G. R.: Biomass burning emissions estimated with a global fire assimilation system based on observed fire radiative power, Biogeosciences, 9, 527-554, doi:10.5194/bg-9-527-2012, 2012.

Koch, D. and Del Genio, A. D.: Black carbon semi-direct effects on cloud cover: review and synthesis, Atmos. Chem. Phys., 10, 7685-7696, doi:10.5194/acp-10-7685-2010, 2010.

Lau, K. M., Kim, M. K., and Kim, K. M.: Asian summer monsoon anomalies induced by aerosol direct forcing: the role of the Tibetan Plateau, Clim. Dynam., 26, 855-864, doi:10.1007/s00382006-0114-z, 2006.

Lee, H.-H., Bar-Or, R. Z., and Wang, C.: Biomass Burning Aerosols and the Low Visibility Events in Southeast Asia, Atmos. Chem. Phys. Discuss., doi:10.5194/acp-2016-504, in review, 2016.
Lee, S.-Y. and Wang, C.: The Response of the South Asian Summer Monsoon to Temporal and Spatial Variations in Absorbing Aerosol Radiative Forcing, J. Climate, 28, 6626-6646, doi:10.1175/JCLI-D-14-00609.1, 2015.

Lee, S.-Y., Shin, H.-J., and Wang, C.: Nonlinear Effects of Coexisting Surface and Atmospheric Forcing of Anthropogenic Absorbing Aerosols: Impact on the South Asian Monsoon Onset, J. Climate, 26, 5594-5607, doi:10.1175/JCLI-D-12-00741.1, 2013.

Lelieveld, J., Evans, J. S., Fnais, M., Giannadaki, D., and Pozzer, A.: The contribution of outdoor air pollution sources to premature mortality on a global scale, Nature, 525, 367-371, doi:10.1038/nature15371, 2015.

Liu, X., Easter, R. C., Ghan, S. J., Zaveri, R., Rasch, P., Shi, X., Lamarque, J.-F., Gettelman, A., Morrison, H., Vitt, F., Conley, A., Park, S., Neale, R., Hannay, C., Ekman, A. M. L., Hess, P., Mahowald, N., Collins, W., Iacono, M. J., Bretherton, C. S., Flanner, M. G., and Mitchell, D.: Toward a minimal representation of aerosols in climate models: description and evaluation in the Community Atmosphere Model CAM5, Geosci. Model Dev., 5, 709-739, doi:10.5194/gmd-5-709-2012, 2012.

Lohmann, U.: A glaciation indirect aerosol effect caused by soot aerosols, Geophys. Res. Lett., 29, 1052, doi:10.1029/2001GL014357, 2002.

Lohmann, U. and Feichter, J.: Global indirect aerosol effects: a review, Atmos. Chem. Phys., 5, 715-737, doi:10.5194/acp-5-7152005, 2005.

Menon, S.: Climate Effects of Black Carbon Aerosols in China and India, Science, 297, 2250-2253, doi:10.1126/science.1075159, 2002.

Morrison, H. and Gettelman, A.: A New Two-Moment Bulk Stratiform Cloud Microphysics Scheme in the Community Atmosphere Model, Version 3 (CAM3). Part I: Description and Numerical Tests, J. Climate, 21, 3642-3659, doi:10.1175/2008JCLI2105.1, 2008.

Neale, R. B., Gettelman, A., Park, S., Chen, C.-C., Lauritzen, P. H., Williamson, D. L., Conley, A. J., Kinnison, D., Marsh, D., Smith, A. K., Vitt, F., Garcia, R., Lamarque, J.-F., Mills, M., Tilmes, S., Morrison, H., Cameron-Smith, P., Collins, W. D., Iacono, M. J., Easter, R. C., Liu, X., Ghan, S. J., Rasch, P. J., and Taylor, M. A.: Description of the NCAR Community Atmosphere Model (CAM 5.0), NCAR Tech. Note TN-486, available at: http://www.cesm.ucar.edu/models/cesm1. 0/cam/docs/description/cam5_desc.pdf (last access: 18 November 2016), 2012.

Page, S. E., Siegert, F., Rieley, J. O., Boehm, H.-D. V., Jaya, A., and Limin, S.: The amount of carbon released from peat and forest fires in Indonesia during 1997, Nature, 420, 61-65, doi:10.1038/nature01131, 2002.

Rosenfeld, D., Lohmann, U., Raga, G. B., O'Dowd, C. D., Kulmala, M., Fuzzi, S., Reissell, A., and Andreae, M. O.: Flood or drought: how do aerosols affect precipitation?, Science, 321, 1309-13, doi:10.1126/science.1160606, 2008.

Rosenfeld, D., Andreae, M. O., Asmi, A., Chin, M., de Leeuw, G., Donovan, D. P., Kahn, R., Kinne, S., Kivekäs, N., Kulmala, M., Lau, W., Schmidt, K. S., Suni, T., Wagner, T., Wild, M., and Quaas, J.: Global observations of aerosol-cloudprecipitation-climate interactions, Rev. Geophys., 52, 750-808, doi:10.1002/2013RG000441, 2014. 
Sena, E. T. and Artaxo, P.: A novel methodology for largescale daily assessment of the direct radiative forcing of smoke aerosols, Atmos. Chem. Phys., 15, 5471-5483, doi:10.5194/acp15-5471-2015, 2015.

Shindell, D. T., Lamarque, J.-F., Schulz, M., Flanner, M., Jiao, C., Chin, M., Young, P. J., Lee, Y. H., Rotstayn, L., Mahowald, N., Milly, G., Faluvegi, G., Balkanski, Y., Collins, W. J., Conley, A. J., Dalsoren, S., Easter, R., Ghan, S., Horowitz, L., Liu, X., Myhre, G., Nagashima, T., Naik, V., Rumbold, S. T., Skeie, R., Sudo, K., Szopa, S., Takemura, T., Voulgarakis, A., Yoon, J.-H., and Lo, F.: Radiative forcing in the ACCMIP historical and future climate simulations, Atmos. Chem. Phys., 13, 2939-2974, doi:10.5194/acp-13-2939-2013, 2013.

Stevens, B. and Feingold, G.: Untangling aerosol effects on clouds and precipitation in a buffered system, Nature, 461, 607-613, doi:10.1038/nature08281, 2009.

Tao, W.-K., Chen, J.-P., Li, Z., Wang, C., and Zhang, C.: Impact of aerosols on convective clouds and precipitation, Rev. Geophys., 50, RG2001, doi:10.1029/2011RG000369, 2012.

Teng, H., Washington, W. M., Branstator, G., Meehl, G. A., and Lamarque, J.-F.: Potential impacts of Asian carbon aerosols on future US warming, Geophys. Res. Lett., 39, L11703, doi:10.1029/2012GL051723, 2012.

Twomey, S.: Pollution and the planetary albedo, Atmospheric Environment, 8, 1251-1256, doi:10.1016/0004-6981(74)90004-3, 1974.

Twomey, S.: The Influence of Pollution on the Shortwave Albedo of Clouds, J. Atmos. Sci., 34, 1149-1152, doi:10.1175/15200469(1977)034<1149:TIOPOT>2.0.CO;2, 1977.

Unger, N., Bond, T. C., Wang, J. S., Koch, D. M., Menon, S., Shindell, D. T., and Bauer, S.: Attribution of climate forcing to economic sectors, P. Natl. Acad. Sci. USA, 107, 3382-3387, doi:10.1073/pnas.0906548107, 2010.

van der Werf, G. R., Randerson, J. T., Giglio, L., Collatz, G. J., Mu, M., Kasibhatla, P. S., Morton, D. C., DeFries, R. S., Jin, Y., and van Leeuwen, T. T.: Global fire emissions and the contribution of deforestation, savanna, forest, agricultural, and peat fires (19972009), Atmos. Chem. Phys., 10, 11707-11735, doi:10.5194/acp10-11707-2010, 2010.
Veira, A., Kloster, S., Schutgens, N. A. J., and Kaiser, J. W.: Fire emission heights in the climate system - Part 2: Impact on transport, black carbon concentrations and radiation, Atmos. Chem. Phys., 15, 7173-7193, doi:10.5194/acp-15-7173-2015, 2015.

Wang, C.: Impact of direct radiative forcing of black carbon aerosols on tropical convective precipitation, Geophys. Res. Lett., 34, L05709, doi:10.1029/2006GL028416, 2007.

Wang, C.: The sensitivity of tropical convective precipitation to the direct radiative forcings of black carbon aerosols emitted from major regions, Ann. Geophys., 27, 3705-3711, doi:10.5194/angeo-27-3705-2009, 2009.

Wang, C.: Anthropogenic aerosols and the distribution of past large-scale precipitation change, Geophys. Res. Lett., 42, 1087610884, doi:10.1002/2015GL066416, 2015.

Wang, C., Kim, D., Ekman, A. M. L., Barth, M. C., and Rasch, P. J.: Impact of anthropogenic aerosols on Indian summer monsoon, Geophys. Res. Lett., 36, L21704, doi:10.1029/2009GL040114, 2009.

Ward, D. S., Kloster, S., Mahowald, N. M., Rogers, B. M., Randerson, J. T., and Hess, P. G.: The changing radiative forcing of fires: global model estimates for past, present and future, Atmos. Chem. Phys., 12, 10857-10886, doi:10.5194/acp12-10857-2012, 2012.

Wiedinmyer, C., Akagi, S. K., Yokelson, R. J., Emmons, L. K., AlSaadi, J. A., Orlando, J. J., and Soja, A. J.: The Fire INventory from NCAR (FINN): a high resolution global model to estimate the emissions from open burning, Geosci. Model Dev., 4, 625641, doi:10.5194/gmd-4-625-2011, 2011.

Wilks, D.: The stippling shows statistically significant gridpoints: How Research Results are Routinely Overstated and Overinterpreted, and What to Do About It, B. Am. Meteorol. Soc., doi:10.1175/BAMS-D-15-00267.1, in press, 2016. 